\title{
Paleoceanography
}

\section{RESEARCH ARTICLE \\ 10.1002/2016PA003001 \\ Dynamical reconstruction of the global ocean state during the Last Glacial Maximum}

Key Points:

- LGM ocean reconstruction with an adjoint-based data assimilation technique

- Physics-based three-dimensional interpolation/extrapolation of existing paleoceanographic data

- More stratified LGM ocean with a stronger but shallower AMOC

Correspondence to:

T. Kurahashi-Nakamura,

tkurahashi@marum.de

\section{Citation:}

Kurahashi-Nakamura, T., A. Paul, and M. Losch (2017), Dynamical reconstruction of the global ocean state during the Last Glacial Maximum, Paleoceanography, 32, 326-350, doi:10.1002/2016PA003001.

Received 7 JUL 2016 Accepted 9 MAR 2017 Accepted article online 17 MAR 2017 Published online 11 APR 2017

\section{Introduction}

\author{
Takasumi Kurahashi-Nakamura1 iD, André Paul' ${ }^{1}$, and Martin Losch ${ }^{2,3}$ iD \\ ${ }^{1}$ MARUM - Center for Marine Environmental Sciences and Faculty of Geosciences, University of Bremen, Bremen, \\ Germany, ${ }^{2}$ Alfred Wegener Institute for Polar and Marine Research, Bremerhaven, Germany, ${ }^{3}$ MARUM - Center for Marine \\ Environmental Sciences, University of Bremen, Bremen, Germany
}

\begin{abstract}
The global ocean state for the modern age and for the Last Glacial Maximum (LGM) was dynamically reconstructed with a sophisticated data assimilation technique. A substantial amount of data including global seawater temperature, salinity (only for the modern estimate), and the isotopic composition of oxygen and carbon (only in the Atlantic for the LGM) were integrated into an ocean general circulation model with the help of the adjoint method, thereby the model was optimized to reconstruct plausible continuous fields of tracers, overturning circulation and water mass distribution. The adjoint-based LGM state estimation of this study represents the state of the art in terms of the length of forward model runs, the number of observations assimilated, and the model domain. Compared to the modern state, the reconstructed continuous sea-surface temperature field for the LGM shows a global-mean cooling of $2.2 \mathrm{~K}$, and the reconstructed LGM ocean has a more vigorous Atlantic meridional overturning circulation, shallower North Atlantic Deep Water (NADW) equivalent, stronger stratification, and more saline deep water.
\end{abstract}

The Last Glacial Maximum (LGM, 19,000-23,000 years before present) [Mix et al., 2001] was the latest peak of cold climate with a global ice volume and an atmospheric carbon dioxide $\left(\mathrm{CO}_{2}\right)$ concentration distinctly different from the present-day values. Although the climatic forcing factors are relatively well known [Solomon et al., 2007], some aspects of the climate system during the LGM are still open to discussion. For example, it is uncertain whether the Atlantic meridional overturning circulation (AMOC) was weaker or stronger in the LGM than in the modern day climate [e.g., McCave et al., 1995; Yu et al., 1996; McManus et al., 2004; Curry and Oppo, 2005; Rutberg and Peacock, 2006; Otto-Bliesner et al., 2007; Negre et al., 2010; Muglia and Schmittner, 2015]. Typically, such a problem has been discussed from the viewpoint of paleoceanographic proxy records, numerical modeling, or both of them. Paul and Schäfer-Neth [2003] incorporated the sea-surface temperature reconstruction by the Glacial Atlantic Ocean Mapping project [Sarnthein et al., 2003] into the forcing fields for their ocean general circulation model (OGCM) and suggested that the AMOC during the LGM had a similar strength and depth to those of the modern counterpart.

An accurate reconstruction of the LGM ocean circulation is fundamentally important to understand the LGM climate, not only because the ocean is an important component of the climate system due to its large storage and transport of heat but also because a different ventilation of the deep ocean presumably led to a reorganization of the marine carbon cycle, thereby affecting the global climate through changes in the concentration of $\mathrm{CO}_{2}$ in the atmosphere [e.g., Sigman and Boyle, 2000; Marchitto et al., 2007; Toggweiler, 2008; Kwon et al., 2011; Tschumi et al., 2011; Ritz et al., 2013; Schmittner and Somes, 2016].

The main goal of this study is an estimate of the circulation and water-mass distribution in the ocean state during the LGM that is statistically consistent, within errors, with observations. As a by-product, the ocean state estimate provides an unbiased, that is, based on model physics, interpolation (or mapping) of the tracer distribution, which is otherwise based on very few and scattered proxy observations. We obtained the state estimate for the LGM ocean by synthesizing a state-of-the-art physical ocean model and several recent paleoceanographic proxy data compilations with a data assimilation technique called the adjoint method [e.g., Wunsch, 1996; Errico, 1997]. We also found a state estimate for the modern ocean with the same method, which served as a first guess for the LGM state estimation with regard to chemical tracers and as a reference state for the resulting LGM state estimate.
○2017. American Geophysical Union. All Rights Reserved. 
Table 1. Data Sets That Were Used for State Estimation in This Study ${ }^{\mathrm{a}}$

\begin{tabular}{lccc} 
Data & Source & Data Coverage & Note \\
\hline Annual SST & MARGO Project Members et al. [2009] & & \\
$\delta^{18} \mathrm{O}_{\text {calcite }}$ & Marchal and Curry [2008] & $9.4 \%$ & Global \\
$\delta^{13} \mathrm{C}_{\text {calcite }}$ & Hesse et al. [2011] & $0.58 \%$ (2.3\% for the ATL) & only for the Atlantic domain \\
& & $0.79 \%(3.2 \%$ for the ATL) & only for the Atlantic domain \\
Temperature & World Ocean Database [Locarnini et al., 2010] & $26 \%$ & $1951-1980$ monthly climatology \\
Salinity & World Ocean Database [Antonov et al., 2010] & $26 \%$ & $1951-1980$ monthly climatology \\
$\delta^{18} \mathrm{O}_{\text {water }}$ & Schmidt et al. [1999] & $4.6 \%$ & only for deeper than $150 \mathrm{~m}$ \\
$\delta^{13} \mathrm{C}_{\mathrm{DIC}}$ & Schmittner et al. [2013] & $7.2 \%$ & only for deeper than $1000 \mathrm{~m}$ \\
\hline
\end{tabular}

aSST stands for sea-surface temperature. The data coverage refers to the surface area (for annual-mean SST data) or the volume (other data) of the ocean when mapped onto the model grid.

Most of the previous data assimilation studies used simplified ocean models to reconstruct the paleocirculation or water mass distribution during the LGM [e.g., Legrand and Wunsch, 1995; Gebbie and Huybers, 2006; Huybers et al., 2007; Burke et al., 2011; Gebbie, 2014], and only a few state estimates for the LGM ocean were based on a general circulation model and the adjoint method [Winguth et al., 2000; Dail, 2012; Dail and Wunsch, 2014]. Compared to previous studies, our study constitutes a significant extension in terms of the total number of observations [cf., Winguth et al., 2000], the model domain [cf., Dail, 2012; Dail and Wunsch, 2014], and the length of model integrations [cf., Winguth et al., 2000; Dail, 2012; Dail and Wunsch, 2014].

\section{Data Sets}

Table 1 and Figure 1 summarize the data sets we used in this study. In the following, we describe the data sets in further detail.

\subsection{Modern Data}

In the context of this study, "the modern ocean" refers to the preindustrial ocean state, because we want to discuss natural climate variability in terms of differences between glacial and interglacial periods. Although the anthropogenic effects should be excluded for that purpose, the further one goes back into the past, the fewer data are available. For the temperature and salinity data, therefore, we adopted monthly climatological data for the entire ocean from 1951 to 1980 from the World Ocean Database (WOD) [Locarnini et al., 2010; Antonov et al., 2010]. However, we excluded several regions from the domain of model-data comparison for our state estimation for the modern ocean (see section 4.2).

To reinforce the constraints by the temperature and salinity observations and to provide a basis for the first guess of the LGM state estimation, data for $\delta^{18} \mathrm{O}_{\text {water }}$ [Schmidt et al., 1999] and $\delta^{13} \mathrm{C}_{\mathrm{DIC}}$ [Schmittner et al., 2013] were also incorporated. Following Dail [2012], near-surface data of $\delta^{18} \mathrm{O}_{\text {water }}$ above $150 \mathrm{~m}$ depth were not included, because these data are affected by the seasonal cycle, which is not included in the oxygen isotope module of our circulation model. Similarly, the $\delta^{13} \mathrm{C}_{\mathrm{DIC}}$ data above a depth of $1000 \mathrm{~m}$ were not used, because this depth range was excluded from the domain of the carbon isotope model (see section 3). The $\delta^{13} C_{D I C}$ data were based on the Global Data Analysis Project (GLODAP) and the CARbon dioxide IN the Atlantic Ocean (CARINA) data synthesis project [Schmittner et al., 2013]. Note that the estimated anthropogenic $\delta^{13} \mathrm{C}$ contribution is substantially smaller than the prescribed data uncertainties of this study (see section 4.2) in most parts of deep ocean below the depth of $1000 \mathrm{~m}$ [Schmittner et al., 2013].

\subsection{LGM Data}

The temperature of seawater not only is a good indicator of the past ocean state but also contributes to driving the ocean circulation through density differences. To date, the most comprehensive compilation of sea-surface temperature (SST) estimates for the LGM ocean including their uncertainties are provided by the Multiproxy Approach for the Reconstruction of the Glacial Ocean Surface (MARGO) project [MARGO Project Members et al., 2009]. Because the SST during the LGM cannot be measured directly, it was obtained from paleoceanographic proxy evidence like the assemblages of planktonic foraminifera. 


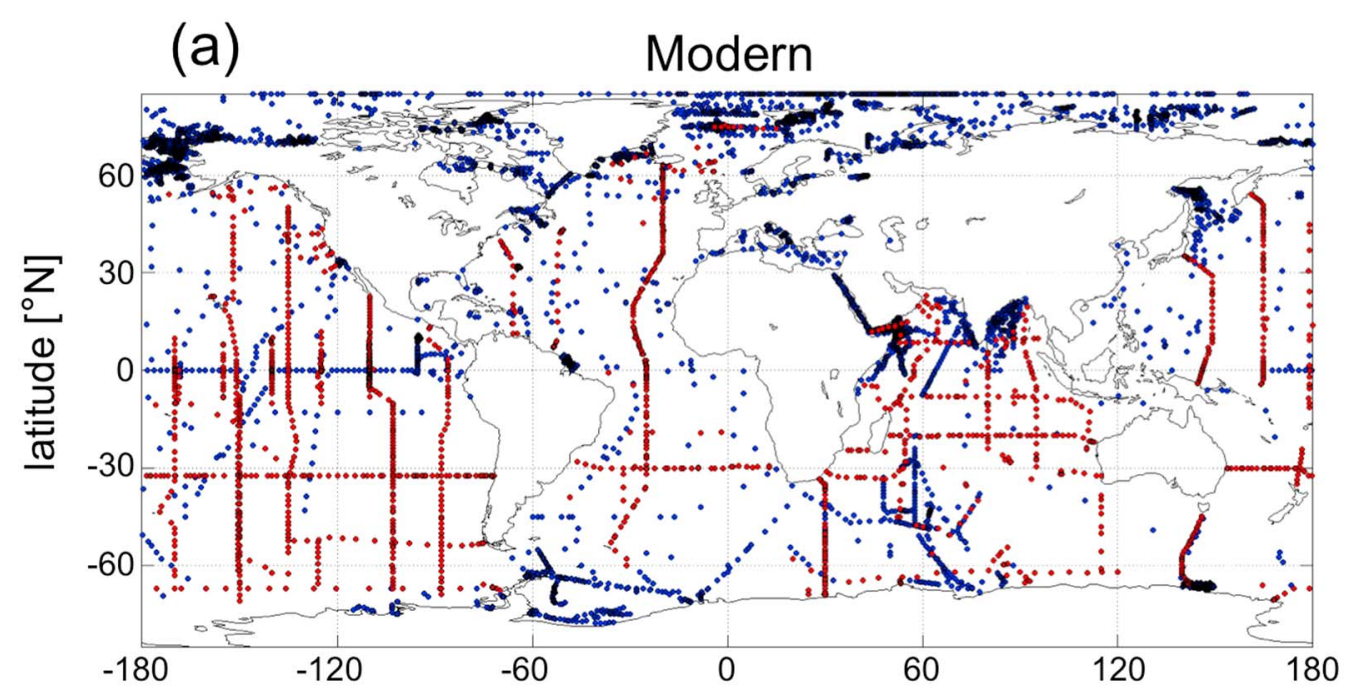

(b) LGM

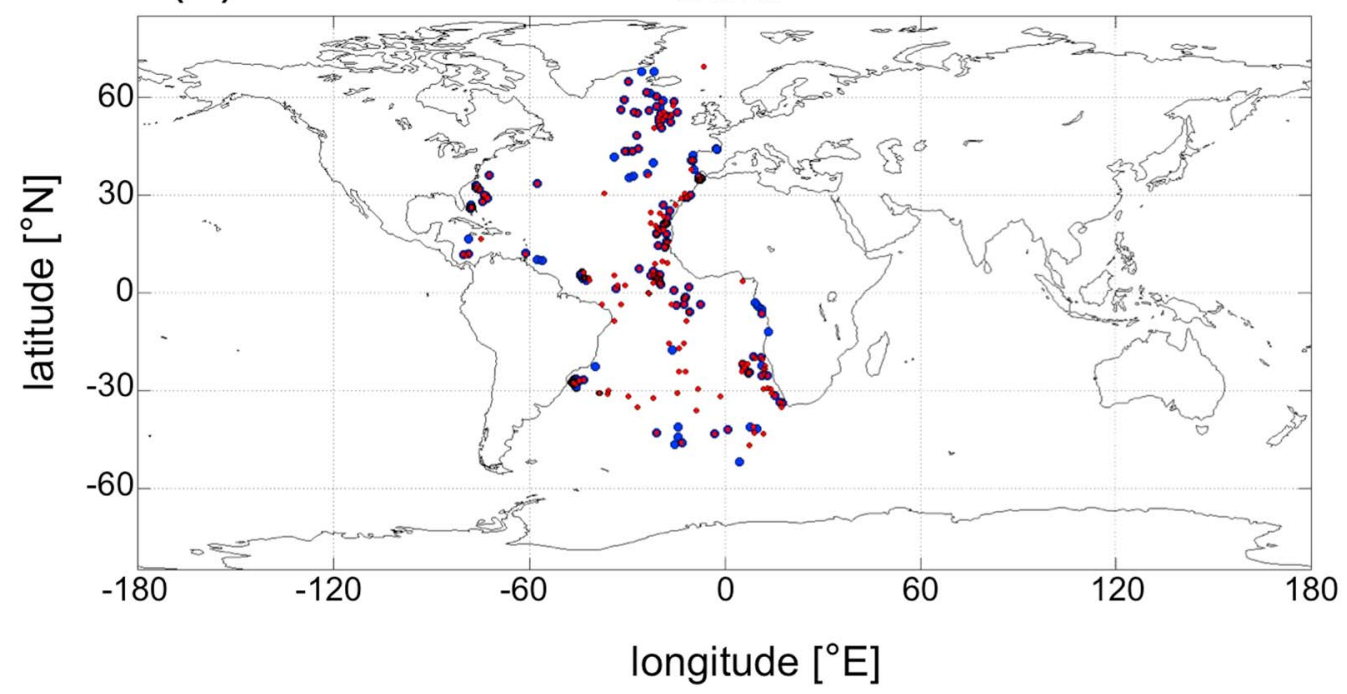

Figure 1. Geochemical tracer locations (a) for the modern state estimate and (b) for the LGM state estimate. Blue dots indicate the locations of $\delta^{18} \mathrm{O}$ data and red dots those of $\delta^{13} \mathrm{C}$ data.

It is important to utilize information from the deep ocean as well, especially when we rely on sparse paleoceanographic proxy data [Kurahashi-Nakamura et al., 2014]. We used the isotopic compositions of seawater for oxygen and carbon as proxy data for the LGM deep ocean. The oxygen isotopic composition of seawater, often expressed as $\delta^{18} \mathrm{O}_{\text {water }}$, is an inert passive tracer that reflects the transport by the ocean circulation once set at the surface. For the LGM, the oxygen isotopic composition of the shells of benthic foraminifera $\left(\delta^{18} \mathrm{O}_{\text {calcite }}\right)$ is a proxy for $\delta^{18} \mathrm{O}_{\text {water, }}$ although it is influenced by the temperature of ambient seawater at the time of calcification. The most comprehensive published compilation of $\delta^{18} \mathrm{O}_{\text {calcite }}$ for the LGM consists of 180 records for the Atlantic Ocean [Marchal and Curry, 2008].

The carbon isotopic composition of the dissolved inorganic carbon of seawater $\left(\delta^{13} C_{D I C}\right)$ is a similarly useful indicator of ocean circulation, but it is also affected by biogeochemical processes (i.e., the remineralization of organic soft tissue). As in the case of oxygen isotopes, $\delta^{13} C_{\mathrm{DIC}}$ for the LGM is recorded in the shells of benthic foraminifera as $\delta^{13} C_{\text {calcite. }}$. We adopted the database compiled by Hesse et al. [2011].

We used the recent compilations of isotopic composition data for the Indian and Pacific Oceans by Oliver et al. [2010] and Peterson et al. [2014] as an independent source of information to assess our state estimate (section 8.1). Although these data sets would complement the Atlantic data [Marchal and Curry, 2008; 
Hesse et al., 2011], we did not include them in the adjoint-based state estimate of this study, because their coverage is very low in the Pacific and Indian Oceans $\left(0.15 \%\right.$ for $\delta^{18} \mathrm{O}$ and $0.62 \%$ for $\delta^{13} \mathrm{C}$ of the combined Indian and Pacific Oceans) and because they also would not substantially increase the data coverage in the Atlantic Ocean (from 2.3 to $3.2 \%$ for $\delta^{18} \mathrm{O}$ and 3.2 to $4.0 \%$ for $\delta^{13} \mathrm{C}$ ). Very sparse data can lead to artefacts around singular data points in the solution, even though the adjoint method provides a dynamical state estimate with the aid of model physics. Further, we designed our experiments as an extension of Dail [2012] and Gebbie [2014] who both used the data sets by Marchal and Curry [2008] and Hesse et al. [2011] by different methods. Our choice to use the data of Oliver et al. [2010] and Peterson et al. [2014] only for independent observations maximizes the comparability with Dail [2012] and Gebbie [2014].

\section{Ocean and Tracer Models}

We employed the Massachusetts Institute of Technology general circulation model (MITgcm). It was configured to solve the Boussinesq, hydrostatic Navier-Stokes equations [Marshall et al., 1997]. Subgrid-scale mixing was parameterized [Gent and McWilliams, 1990]. A dynamic-thermodynamic sea-ice model was coupled to the ocean model [Losch et al., 2010]. We used a cubed-sphere grid system that avoided converging grid lines and pole singularities [Adcroft et al., 2004] and had six faces with $32 \times 32$ horizontal grid cells and 15 vertical layers, respectively. The MITgcm was particularly designed for ocean state estimation projects [e.g., Stammer et al., 2002; Wunsch and Heimbach, 2006; Köhl and Stammer, 2008; Forget et al., 2015; Köhl, 2015]. For that purpose, the computer code can be differentiated by automatic differentiation using the source-to-source compiler TAF [Giering and Kaminski, 1998; Heimbach et al., 2005] to generate exact and efficient "adjoint" model code.

To simulate $\delta^{18} \mathrm{O}_{\text {water }}$ and $\delta^{13} \mathrm{C}_{\mathrm{DIC}}$, we adopted highly simplified models similar to previous data assimilation studies [Marchal and Curry, 2008; Dail, 2012]. The oxygen isotopic composition of seawater $\delta^{18} \mathrm{O}_{\text {water }}$ was treated as a passive and conservative tracer with a fixed boundary condition at a certain depth level (i.e., by prescribing a Dirichlet boundary condition at a depth of $150 \mathrm{~m}$ ). The surface ocean shallower than $150 \mathrm{~m}$ is not part of the model domain for $\delta^{18} \mathrm{O}_{\text {water }}$ (also see section 2.1).

The carbon isotopic composition of the dissolved inorganic carbon $\delta^{13} C_{D I C}$ was treated in a similar way, but there were two differences due to the additional process of remineralization of organic carbon. First, the decomposed, isotopically "lighter" organic carbon affects the isotopic composition of dissolved inorganic carbon (DIC). Accordingly, we added a source term to the conservation equation for $\delta^{13} C_{D I C}$ :

$$
S_{\delta^{13} C_{\mathrm{DIC}}}=\frac{\alpha}{\lambda}\left(\delta^{13} \mathrm{C}_{\mathrm{org}}-\delta^{13} \mathrm{C}_{\mathrm{DIC}}\right)
$$

where $\alpha$ is a factor to control the magnitude of the remineralization effect, $\lambda$ is a standard relaxation timescale, $\delta^{13} \mathrm{C}_{\text {org }}$ is the $\delta^{13} \mathrm{C}$ value of the organic carbon, and $\delta^{13} \mathrm{C}_{\mathrm{DIC}}$ is the in situ $\delta^{13} \mathrm{C}$ value of DIC. Assuming an uniform amount of decomposed organic carbon below a depth of $1000 \mathrm{~m}$, the reference value of $\lambda$ was determined from the modern amount of total remineralization in the global ocean deeper than $1000 \mathrm{~m}$ [Del Giorgio and Duarte, 2002] and the volume of the corresponding water body, so that $1 / \lambda=0.6 \times 10^{-4}$ year $^{-1}\left[\mathrm{Marchal}^{2}\right.$ and Curry, 2008]. That value corresponded to the central value of the original estimate with an uncertainty of $\pm 10 \%$ [Del Giorgio and Duarte, 2002]. The value of $\delta^{13} \mathrm{C}_{\text {org }}$ was assumed to be $-20 \%$ [Goericke and Fry, 1994].

The second difference from the treatment of $\delta^{18} \mathrm{O}_{\text {water }}$ was that we excluded the depths shallower than $1000 \mathrm{~m}$ from the model domain. Accordingly, a Dirichlet boundary condition was imposed at a depth of $1000 \mathrm{~m}$. The remineralization rate is much higher and highly depth-dependent at these depths [e.g., Yamanaka and Tajika, 1996]; hence, the model was not suitable for this depth range.

\section{State Estimation Procedures}

\subsection{Common Framework}

The quality of the model optimization or state estimation was quantified by introducing an objective function $J$ :

$$
J=J_{\text {data }}+J_{\mathrm{SSH}}+J_{\text {ctrl }},
$$

where $J_{\text {data }}$ was the model-data misfit, $J_{\text {SSH }}$ was a penalty term for the drift of the global-mean sea-surface height (SSH), and $J_{\text {ctrl }}$ imposed penalties for the deviations of control variables from their first-guess values and hence represents a regularization of the inverse problem. Here control variables mean variables that are adjusted to improve the model-data misfit. 
The first term of equation (2) was formulated as follows:

$$
J_{\text {data }}=\sum_{X}\left(\mathbf{X}_{\text {model }}-\mathbf{X}_{\mathrm{obs}}\right)^{T} \mathbf{W}_{\mathbf{X}}\left(\mathbf{X}_{\text {model }}-\mathbf{X}_{\mathrm{obs}}\right)
$$

where $X$ was the index showing the category of data, $\mathbf{X}_{\text {model }}$ was the model results for that category, $\mathbf{X}_{\mathrm{obs}}$ was the corresponding observation, and $\mathbf{W}_{X}$ was the weight matrix that consisted of the inverse of the error covariances. For simplicity and because estimating actual covariances is difficult, we followed a common practice in previous applications of the adjoint method [Stammer et al., 2002; Köhl et al., 2007; Dail and Wunsch, 2014] and assumed that all errors are uncorrelated.

The second term of equation (2) became

$$
J_{S S H}=W_{s S h}\left(S S H_{1}-S S H_{0}\right)^{2}
$$

where $\mathrm{W}_{\text {ssh }}$ was a weight factor and $\mathrm{SSH}_{1}$ and $\mathrm{SSH}_{0}$ were the final and initial values of the global-mean sea-surface height, respectively. The term $J_{\mathrm{SSH}}$ is an implicit constraint on the global-mean salinity, because it regulates the total volume of seawater. In particular, for the LGM state estimation that did not have explicit salinity data, it was the only constraint on salinity. The weight factor $W_{\text {ssh }}$ was the inverse of the square of an assumed allowed deviation $(0.1 \mathrm{~m})$. However, in order to ensure a sufficiently small SSH drift, a $10^{4}$ times greater weight (i.e., stricter constraint) was given to $J_{\text {SSH }}$ if the absolute value of the drift exceeded 2 standard deviations.

The last term of equation (2) was taken as

$$
\begin{aligned}
& J_{\text {ctrl }}=\frac{N_{\text {data }}}{N_{\text {ctrl }}} \\
& \times\left[\left(\mathbf{T}_{\mathbf{0}}{ }^{\text {adj }}-\mathbf{T}_{\mathbf{0}}{ }^{1 \mathrm{st}}\right)^{T} \mathbf{W}_{\mathrm{T}_{0}}\left(\mathbf{T}_{\mathbf{0}}{ }^{\text {adj }}-\mathbf{T}_{\mathbf{0}}{ }^{1 \text { st }}\right)\right. \\
& +\left(\mathbf{S}_{\mathbf{0}}{ }^{\text {adj }}-\mathbf{S}_{\mathbf{0}}{ }^{1 \mathrm{st}}\right)^{T} \mathbf{W}_{\mathrm{S}_{0}}\left(\mathbf{S}_{\mathbf{0}}{ }^{\text {adj }}-\mathbf{S}_{\mathbf{0}}{ }^{1 \mathrm{st}}\right) \\
& +\sum_{i}\left(\mathbf{F}(i)^{\mathrm{adj}}-\mathbf{F}(i)^{1 \mathrm{st}}\right)^{T} \mathbf{W}_{\mathrm{F}(\mathrm{i})}\left(\mathbf{F}(i)^{\mathrm{adj}}-\mathbf{F}(i)^{1 \mathrm{st}}\right) \\
& +\left(\mathbf{K}^{\text {adj }}-\mathbf{K}^{1 \mathrm{st}}\right)^{T} \mathbf{W}_{\mathrm{K}}\left(\mathbf{K}^{\mathrm{adj}}-\mathbf{K}^{1 \mathrm{st}}\right) \\
& +\left(\mathbf{O}_{\mathbf{0}}{ }^{\text {adj }}-\mathbf{O}_{\mathbf{0}}{ }^{1 s t}\right)^{T} \mathbf{W}_{\mathrm{O}_{0}}\left(\mathbf{O}_{\mathbf{0}}{ }^{\text {adj }}-\mathbf{O}_{\mathbf{0}}{ }^{1 s t}\right) \\
& +\left(\mathbf{C}_{\mathbf{0}}{ }^{\text {adj }}-\mathbf{C}_{\mathbf{0}}{ }^{1 \text { st }}\right)^{T} \mathbf{W}_{\mathrm{C}_{0}}\left(\mathbf{C}_{\mathbf{0}}{ }^{\text {adj }}-\mathbf{C}_{\mathbf{0}}{ }^{1 \text { st }}\right) \\
& \left.+W_{\alpha}\left(\alpha^{\text {adj }}-\alpha^{1 s t}\right)^{2}\right] \text {, }
\end{aligned}
$$

where $N_{\text {data }}$ was the number of model-data pairs, $N_{\text {ctrl }}$ the number of control variables, $\mathbf{T}_{\mathbf{0}}$ the initial temperature field, $\mathbf{S}_{\mathbf{0}}$ the initial salinity field, $\mathbf{F}$ the atmospheric forcings, $i$ indices indicating the kind of forcings, $\mathbf{K}$ the vertical diffusion coefficient, $\mathbf{O}_{\mathbf{0}}$ the initial $\delta^{18} \mathrm{O}_{\text {water }}$ field, $\mathbf{C}_{\mathbf{0}}$ the initial $\delta^{13} \mathrm{C}_{\mathrm{DIC}}$ field, $\mathbf{W}$ the weight matrices for each quantity, and $W_{\alpha}$ was the weight factor for the penalty for $\alpha$. The superscript "adj" meant adjusted values (i.e., values in the current iteration), and "1st" meant first-guess values (i.e., values in the first iteration). The weight matrices were the inverse of the error covariances. The prior uncertainties assumed for the 200 year or longer state estimations are summarized in Table 2 . For $W_{\alpha}$, however, a greater penalty was given for deviations larger than 2 standard deviations as in the $W_{\text {ssh }}$ case, because we were not able to evaluate the consistency between $\alpha^{\text {adj }}$ and biogeochemical processes that were not explicitly included in our simplified model.

The factor $N_{\text {data }} / N_{\text {ctrl }}$ was only used for the LGM state estimation to balance $J_{\text {ctrl }}$ and $J_{\text {data }}$, because $N_{\text {ctrl }}$ was much larger than $N_{\text {data }}$ for the LGM. Without this factor, the model did not move away from the first guess during optimization. It should be noted that $J_{\text {ctrl }}=0$ (i.e., no adjustment) at the beginning of the state estimation procedure and that it generally increases with the progress of optimization. The balancing factor $N_{\text {data }} / N_{\text {ctrl }}$ served to compensate for the increase in $J_{\text {ctrl }}$ with a reduction in $J_{\text {data }}$ of a comparable magnitude, which allowed for a decrease of the total cost $(J)$.

We sought a model ocean that corresponded to the minimum value of the objective function, and we assumed that such an optimized model ocean provided the best estimate for the ocean state. The adjoint method was used to calculate the gradient of the objective function with respect to the selected control variables (i.e., model inputs and parameters that determine the model state), hence the direction to its minimum. 


\begin{tabular}{|c|c|c|}
\hline Variables & Uncertainty & Units \\
\hline Initial temperature & $3.2 \times 10^{0}$ & $\mathrm{~K}$ \\
\hline Initial salinity & $3.2 \times 10^{-1}$ & psu \\
\hline Surface air temperature & $1.0 \times 10^{0}$ & K \\
\hline Specific humidity & $1.0 \times 10^{-3}$ & $\mathrm{~kg} / \mathrm{kg}$ \\
\hline Precipitation & $1.0 \times 10^{-8}$ & $\mathrm{~m} / \mathrm{s}$ \\
\hline Downward shortwave radiation & $1.0 \times 10^{0}$ & $\mathrm{~W} / \mathrm{m}^{2}$ \\
\hline Wind velocities & $3.2 \times 10^{-1}$ & $\mathrm{~m} / \mathrm{s}$ \\
\hline Vertical diffusion coefficient & $3.2 \times 10^{-6}$ & $\mathrm{~m}^{2} / \mathrm{s}$ \\
\hline Initial $\delta^{18} \mathrm{O}_{\text {water }}$ & $3.2 \times 10^{-1}$ & $\%$ \\
\hline Initial $\delta^{13} C_{\mathrm{DIC}}$ & $3.2 \times 10^{-1}$ & $\%$ \\
\hline Remineralization factor & $1.0 \times 10^{-1}$ & - \\
\hline
\end{tabular}

With this information one can iteratively approach the optimized state by incrementally improving the control variables; in our case this was accomplished with a quasi-Newton algorithm [Gilbert and Lemaréchal, 1989].

For the state estimation with the adjoint method, we needed to prepare a starting point of the iterative search (first guess). It is desirable to have a first guess as good as possible for a successful estimation process. This should be emphasized especially when a long state estimation (i.e., a state estimation with longer forward simulations) is made, because in such a case the model state can show a large drift that may cause great difficulties with the adjoint method [Dail, 2012]. Therefore, although we aimed at a state estimation of 200 years or longer, we started out from a 20 year preparatory estimation only for the physical ocean state, followed by a gradual extension of the estimation length with the "carry-over" technique suggested by Dail [2012].

The problem was further preconditioned and regularized by normalizing every control variable according to the characteristic scale of each variable, which typically has a scale similar to the uncertainties, so that we could adjust all control variables in a balanced manner. The corresponding fields were smoothed with a 9-point spatial smoothing filter.

\subsection{Modern State Estimation}

The first guess fields of the physical ocean state (i.e., for the preparatory phase) was the reference state of Kurahashi-Nakamura et al. [2014], which was simulated by the MITgcm driven by external atmospheric forcing fields based on the protocol of the Coordinated Ocean-ice Reference Experiments (COREs) project [Griffies et al., 2009].

To calculate $J_{\text {data }}$ for the modern state estimation, we took the difference between the model results that were averaged over the last 10 years of a model integration and the observations (equation (3)). While the time-averaged model results for $\delta^{18} \mathrm{O}$ and $\delta^{13} \mathrm{C}$ did not take into account seasonal changes, for temperature and salinity we took the difference between the monthly-mean model results and the corresponding monthly-mean data. We determined the prior uncertainties of the temperature and salinity data from the standard error of the monthly mean, although $1 \mathrm{~K}$ and $0.1 \mathrm{psu}$ were added considering uncertainties due to data representativeness and model errors. For example, the observations are scattered with respect to time and do not cover the time window evenly, the pattern of the scatter is different from grid cell to grid cell, and the spatial resolution of the model would be too coarse to accurately capture the observations that reflected smaller-scale processes. Moreover, the climatological data, which resulted from interannually varying atmospheric forcing, could not be reproduced accurately, because our model was driven by purely periodic atmospheric forcing. Because it was beyond the scope of this study to obtain precise values for these uncertainties, they were determined in an ad hoc way. However, the overall uncertainties had a magnitude similar to those used in another data assimilation study [Gebbie, 2014] that was based on the World Ocean Circulation Experiment climatology [Gouretski and Koltermann, 2004]. 
In this study's framework of data assimilation, the adjustment of atmospheric forcings was controlled to avoid too large deviations from the first-guess values. The deviation, however, was only assessed by a single scalar number in the penalty terms (equation (5)) of the objective function; hence, it does not necessarily guarantee that the adjusted atmospheric forcings are within a reasonable range in every spatial and temporal location. Actually, in a preliminary state estimation for the modern ocean assimilating all available data from the WOD (see in the appendix), the adjusted atmospheric forcings assumed physically unreasonable values (e.g., negative precipitation, negative specific humidity, and too low air temperature) in several regions, although the lumped penalty terms had acceptable values. We took three measures against this problem of the preceding run. First, to remove quasi-isolated grid cells along coasts that did not have sufficient communication with the open ocean, we slightly modified the model bathymetry; otherwise, such grid cells can have unreasonable tracer concentration (e.g., too high salinity). Second, we excluded regions having unreasonable atmospheric forcings (see in the appendix for the definition) from the domain of model-data comparison with regard to the temperature and salinity. Practically, we gave zero weights for $J_{\text {data }}$ to any temperature and salinity data located in such regions, which implicitly assumed that the prior uncertainties were actually much larger than the prescribed values in those regions. As a result, the data coverage of the modern temperature and salinity data was reduced by $21 \%$ from the original one (also see in the appendix). Third, because the unreasonable atmospheric forcings were not eliminated completely even with the reduced data sets, we set an upper and lower bound for air temperature, specific humidity, and precipitation and forcibly replaced any remaining unreasonable forcings with those values for each forward model run in the iterative searching. These alterations enabled us to obtain a more plausible ocean state consistent with reasonable inputs from the atmosphere.

For the geochemical tracers, the first-guess initial and boundary conditions of $\delta^{18} \mathrm{O}_{\text {water }}$ and $\delta^{13} \mathrm{C}_{\mathrm{DIC}}$ for the 200 year estimation were the optimized states given by the preceding state estimation with the original (i.e., unreduced) WOD data sets. The uncertainties for $\delta^{18} \mathrm{O}_{\text {water }}$ and $\delta^{13} \mathrm{C}_{\mathrm{DIC}}$ data were assumed to be $0.2 \%$ [Dail, 2012; Gebbie, 2014]. They also implicitly contained various sources of uncertainties such as sampling error, time variation of the tracers and errors due to the highly simplified geochemical tracer model [Dail, 2012].

\subsection{LGM State Estimation}

Similarly to the modern case, the model results were averaged over the last 10 years and compared with the reconstructions by the MARGO project to calculate the model-data misfits for the SST. We used prior data errors derived from the uncertainty estimated for each individual data point by the MARGO project [MARGO Project Members et al., 2009]. MARGO uncertainty estimates are conservative and meant to give an upper bound.

For the model-data comparison of the geochemical tracers, we calculated $\delta^{18} \mathrm{O}_{\text {calcite }}$ from $\delta^{18} \mathrm{O}_{\text {water }}$ as a function of seawater temperature (T) [Marchal and Curry, 2008]:

$$
\delta^{18} \mathrm{O}_{\text {calcite }}=3.35+0.97 \cdot \delta^{18} \mathrm{O}_{\text {water }}-0.21 \cdot T
$$

$\delta^{13} \mathrm{C}_{\text {calcite }}$ was obtained for $\delta^{13} \mathrm{C}$ model-data comparison from the following conversion [Marchal and Curry, 2008]:

$$
\delta^{13} \mathrm{C}_{\text {calcite }}=0.13+0.90 \cdot \delta^{13} \mathrm{C}_{\mathrm{DIC}}
$$

For both $\delta^{18} \mathrm{O}$ and $\delta^{13} \mathrm{C}$, a prior error of $0.2 \%$ was assumed for the data uncertainty according to Marchal and Curry [2008] and Dail [2012], that is, the same value as for the modern ocean case.

The original first guess of the physical ocean state for the LGM was made by spinning up the model forward in time for 2000 model years with climatological monthly-mean atmospheric forcing fields derived from an LGM simulation with the comprehensive Community Climate System Model Version 3 (CCSM3) [Merkel et al., 2010]. The LGM bathymetry was created by remapping of the ICE-5G topography [Peltier, 2004] onto our model grid. The initial temperature and salinity states were taken from modern observations [Levitus, 1982], although a $1.1 \%$ offset was added to the salinity to take into account the mean salinity change due to the lower sea level during the LGM [Adkins and Schrag, 2001]. This original first guess was improved by a sequence of preparatory state estimations of up to 100 years. We used the improved first guess to initialize a 400 year state estimation that was the major achievement of this study.

The first-guess initial and boundary conditions of $\delta^{18} \mathrm{O}_{\text {water }}$ for the 200 year state estimation were separately prepared by adding a constant offset of 1.1\%o [Duplessy et al., 2002] to the modern distribution given by 
the experiment shown in the appendix. Similarly, the first-guess initial and boundary conditions of $\delta^{13} C_{D I C}$ were constructed by adding $0.15 \%$ o uniformly for depths shallower than $1500 \mathrm{~m}$ and by subtracting $0.6 \%$ for depths deeper than $2000 \mathrm{~m}$ according to the average difference between the late Holocene and the LGM [Hesse et al., 2011].

\subsection{Experimental Design}

The main part of this paper describes four state estimations: two for the modern day and two for the LGM. In both cases, a 200 year state estimation was carried over to a 400 year state estimation (i.e., a 400 year model run for each iteration). The 200 year state estimation for the modern day and for the LGM are called MOD200 and LGM200, and the 400 year estimation MOD400 and LGM400, respectively.

Considering the equilibrium time scales for tracer distributions in the global ocean [Wunsch and Heimbach, 2008], 200 years would be too short to reach consistency between the surface boundary conditions and the physical and geochemical tracer distributions in the deep ocean and thus the thermohaline circulation. This motivated us to conduct longer state estimations (i.e., state estimations with longer forward simulations).

However, longer state estimations cause greater computational costs and can be difficult to achieve because of the potentially unreasonably large drift (see section 4.1). Therefore, we adopted 400 years as the length of the extended state estimations. Although it was still not long enough compared to the equilibrium time scale especially for the very deep ocean in the South Atlantic and Southern Ocean [Wunsch and Heimbach, 2008], it led to the longest adjoint-based ocean state estimation for the LGM that has been achieved to date. The 400 year state estimations ("MOD400" for the modern day and "LGM400" for the LGM) were initialized from the optimized states obtained by MOD200 and LGM200, respectively. For the LGM, we assumed $\sqrt{10}$ times smaller uncertainties of the control variables in the penalty terms than those for LGM200, which corresponded to 10 times larger weights, because the control variables had been already improved in LGM200. That was also helpful to stabilize the longer adjoint run. For the modern case, however, we kept the same uncertainties for MOD400, because we judged that the improvement in MOD200 was not enough especially for the temperature and salinity distributions and that considerable adjustments of the control variables were still necessary.

As a general behavior of our state estimation, a rapid reduction of the total cost $(J)$ occurred at an early stage of the iterative procedure, followed by a phase of a very slow reduction seemingly approaching a nonzero limit value. Because it was then highly time consuming to obtain a substantial further decrease, the iterative search was stopped when $J$ was reduced by less than $1 \%$ during the last 10 simulations.

\section{Evaluation of Model-Data Misfit}

5.1. Measures of Model-Data Misfit

To quantify and evaluate how well the model was optimized in terms of the agreement with observation, several measures of fit were introduced and used throughout this study. The most straightforward way is to follow the development of the objective function. In particular, it is practical to observe the normalized total cost $\left(J^{\prime}\right)$, namely, the normalized root-mean-square misfit [e.g., Köhl et al., 2007; Dail, 2012; Kurahashi-Nakamura et al., 2014]. This idea is based on the principles of the $\chi$ square test. When a proper model-data agreement is achieved, the normalized cost (i.e., objective function divided by the number of model-data comparisons) should be of the order of 1 , which implies that the model is statistically consistent with the data within the prior uncertainty.

A similar idea was applicable to the two penalty costs $\left(J_{\mathrm{SSH}}\right.$ and $\left.J_{\mathrm{ctr}}\right)$. The normalization made no difference for $J_{\mathrm{SSH}}$, because it only had one comparison term. As to $J_{\mathrm{ctrl}}$, the normalized cost was calculated by dividing the original $J_{\text {ctrl }}$ by the total number of control variables and also by $N_{\text {data }} / N_{\text {ctrl }}$ (cf. equation (5)). The magnitude of the normalized control-variable adjustments should be smaller than 1 if the adjustments stay within the assumed allowable deviations from the first-guess values.

Further indices that indicate the quality of the model-data match would be a "fraction within $2 \sigma$ and $1 \sigma^{\prime \prime}$ (hereafter, FW $2 \sigma$ and $\mathrm{FW} 1 \sigma$ ). For grid cells with any data points, the ratio of model results that are within the range of $\pm 2 \sigma( \pm 1 \sigma)$ of the corresponding data should be around $95 \%$ (68\%), if the model results were considered to be statistically consistent with the data within random noise. 
Table 3. Terms of the Objective Function (the Normalized Costs $J^{\prime}$ ), the Fraction Within $2 \sigma$ (FW2 $\sigma$ ), and Within $1 \sigma$ (FW $\left.1 \sigma\right)$ for the Modern State Estimates ${ }^{\mathrm{a}}$

\begin{tabular}{|c|c|c|c|c|c|c|c|c|c|c|c|c|c|c|c|}
\hline & & \multicolumn{3}{|c|}{$\mathrm{T}$} & \multicolumn{3}{|c|}{$\mathrm{S}$} & \multicolumn{3}{|c|}{$\delta^{18} \mathrm{O}$} & \multicolumn{3}{|c|}{$\delta^{13} \mathrm{C}$} & \multirow[b]{2}{*}{$J_{S S H}^{\prime}$} & \multirow[b]{2}{*}{$J_{\mathrm{ctrl}}^{\prime}$} \\
\hline & & $J_{T}^{\prime}$ & $\mathrm{FW} 2 \sigma$ & $\mathrm{FW} 1 \sigma$ & $J_{S}^{\prime}$ & $\mathrm{FW} 2 \sigma$ & $\mathrm{FW} 1 \sigma$ & $J_{018}^{\prime}$ & $\mathrm{FW} 2 \sigma$ & $\mathrm{FW} 1 \sigma$ & $J_{\mathrm{C} 13}^{\prime}$ & $\mathrm{FW} 2 \sigma$ & $\mathrm{FW} 1 \sigma$ & & \\
\hline \multicolumn{2}{|c|}{ Original First Guess } & 2.4 & $89 \%$ & $53 \%$ & 6.4 & $77 \%$ & $58 \%$ & & & & & & & & \\
\hline \multirow[t]{2}{*}{ MOD200 } & $1 \mathrm{st}$ & 1.5 & $94 \%$ & $72 \%$ & 2.5 & $87 \%$ & $65 \%$ & 1.7 & $94 \%$ & $82 \%$ & 1.8 & $86 \%$ & $55 \%$ & $3.8 \times 10^{6}$ & 0.0 \\
\hline & opt & 1.5 & $94 \%$ & $72 \%$ & 2.4 & $87 \%$ & $66 \%$ & 1.7 & $94 \%$ & $82 \%$ & 1.5 & $91 \%$ & $60 \%$ & 0.55 & $9.4 \times 10^{-5}$ \\
\hline \multirow[t]{2}{*}{ MOD400 } & $1 \mathrm{st}$ & 1.5 & $93 \%$ & $69 \%$ & 2.6 & $86 \%$ & $65 \%$ & 1.7 & $94 \%$ & $80 \%$ & 2.3 & $80 \%$ & $52 \%$ & 3.2 & 0.0 \\
\hline & opt & 1.5 & $93 \%$ & $69 \%$ & 2.6 & $86 \%$ & $65 \%$ & 1.4 & $96 \%$ & $85 \%$ & 1.8 & $85 \%$ & $61 \%$ & 3.2 & $2.1 \times 10^{-4}$ \\
\hline
\end{tabular}

a For MOD200 and MOD400, the upper row shows the first-guess values and the lower row shows the optimized values, respectively. The top row shows the original first-guess values (i.e., before the preparatory runs) for temperature and salinity.

\subsection{Modern State Estimation}

The improvement of model-data misfits for the modern state estimations are summarized in Table 3 . For the physical tracers (i.e., temperature and salinity), a substantial amount of the cost decrease was achieved in the preparatory phase. With the help of the improved first guess, a further decrease led to acceptable normalized costs (1.5 for the temperature and 2.4 for the salinity) in MOD200. Without the preparatory phase, 200 year state estimations were hardly able to generate a decrease of costs (not shown). The indices FW $2 \sigma$ and FW $1 \sigma$ for temperature after the optimization were $94 \%$ and $72 \%$, respectively. Combined with the normalized cost, these values indicate that the model was successfully fitted to the temperature data. The results for salinity ( $87 \%$ and $65 \%$ ) were somewhat worse than for temperature, although the optimized value of FW $1 \sigma$ nearly met the requirement.

The synthesis of the geochemical tracers in MOD200 was as good as for the physical tracers. For the $\delta^{18} \mathrm{O}$ component, although the optimized value of $J_{\mathrm{O} 18}^{\prime}$ was somewhat larger than 1, the indices FW $2 \sigma$ and FW $1 \sigma$ met the requirements, suggesting that the synthesis of the $\delta^{18} \mathrm{O}$ data was largely successful. For $\delta^{13} \mathrm{C}$, all the three measures were improved through the state estimation scheme, closely approaching the required values.

Lastly, the SSH drift after the optimization was $7.4 \times 10^{-2} \mathrm{~m} / 200 \mathrm{yr}$ to give $\mathrm{J}_{\mathrm{SSH}}^{\prime}=0.55$, which was well below the allowed magnitude, which indicated that the penalty term in the objective function was actually effective in minimizing the SSH changes. Similarly, $J_{\text {ctrl }}^{\prime}$ was smaller than 1, which showed that the magnitude of the control-variable adjustments was acceptable. We also needed to ensure that the total adjustment of control variables including the preparatory phase was not excessively large. To assess the deviation from the original first-guess values (i.e., the values before the preparatory runs), we calculated the normalized total adjustments assuming the total uncertainties for the air temperature, the downward shortwave radiation, and the wind velocity components to be $10 \mathrm{~K}, 10 \mathrm{~W} / \mathrm{m}^{2}$, and $1.0 \mathrm{~m} / \mathrm{s}$, respectively. It yielded the normalized adjustment of 0.1 , which showed that the adjustments were in a reasonable range.

Using the carry-over technique again, we extended the 200 year state estimation to a 400 year estimation (MOD400). Although a dramatic further improvement of the model-data misfit did not occur for the physical tracers, at least we could keep almost as good results as those in MOD200 so that we were able to show that our results were robust with regard to the increased length of the state estimation. The model-data misfits for $\delta^{18} \mathrm{O}$ were improved not only compared to the first guess but also compared to MOD200, indicating a successful synthesis of those data. On the other hand, the model-data misfits for $\delta^{13} \mathrm{C}$ were slightly worse than in MOD200 at the expense of the longer run ensuring a more equilibrated tracer distribution.

On the whole, the optimized normalized cost in MOD400 was somewhat higher than 1 for all our measures of model-data misfit. However, it is known that the optimization with the adjoint method does not always yield a normalized cost for the model-data misfit as small as one [e.g., Köhl et al., 2007]. Furthermore, $J_{\text {SSH }}^{\prime}$ and $J_{\text {ctrl }}^{\prime}$ were readily within the allowed ranges.

\subsection{LGM State Estimation}

The improvement of the model-data misfits for the LGM state estimations are summarized in Table 4. Both in LGM200 and LGM400, all three indicators for SST show that the optimized model was statistically consistent with the SST data. In fact, the model was already in accordance with the data at the initial state of LGM200 as a result of the preparatory estimation. Similarly to the modern case, the preparatory phase greatly helped to carry out the 200 year state estimation without severe problems. For the $\delta^{18} \mathrm{O}$ component, the FW $2 \sigma$ and 
Table 4. Terms of the Objective Function (the Normalized Costs $J^{\prime}$ ), the Fraction Within $2 \sigma$ (FW2 $\sigma$ ) and Within $1 \sigma(\mathrm{FW} 1 \sigma)$ for the LGM State Estimates ${ }^{\mathrm{a}}$

\begin{tabular}{|c|c|c|c|c|c|c|c|c|c|c|c|c|}
\hline & & \multicolumn{3}{|c|}{ SST } & \multicolumn{3}{|c|}{$\delta^{18} \mathrm{O}$} & \multicolumn{3}{|c|}{$\delta^{13} \mathrm{C}$} & \multirow[b]{2}{*}{$J_{\mathrm{SSH}}^{\prime}$} & \multirow[b]{2}{*}{$J_{c t r l}^{\prime}$} \\
\hline & & $\overline{J_{S S T}^{\prime}}$ & $\mathrm{FW} 2 \sigma$ & $\overline{\mathrm{FW} 1 \sigma}$ & $\overline{J^{\prime} 18}$ & FW $2 \sigma$ & $\overline{\mathrm{FW} 1 \sigma}$ & $\overline{J_{C 13}^{\prime}}$ & $\mathrm{FW} 2 \sigma$ & $\overline{\mathrm{FW} 1 \sigma}$ & & \\
\hline \multicolumn{2}{|c|}{ Original First Guess } & 2.3 & $84 \%$ & $54 \%$ & & & & & & & & \\
\hline \multirow[t]{2}{*}{ LGM200 } & 1st & 0.89 & $95 \%$ & $74 \%$ & 5.3 & $69 \%$ & $42 \%$ & 4.1 & $76 \%$ & $50 \%$ & $2.0 \times 10^{5}$ & 0.0 \\
\hline & opt & 0.89 & $96 \%$ & $74 \%$ & 1.5 & $95 \%$ & $67 \%$ & 1.9 & $89 \%$ & $60 \%$ & 0.093 & 0.028 \\
\hline \multirow[t]{2}{*}{ LGM400 } & $1 s t$ & 0.88 & $95 \%$ & $74 \%$ & 1.6 & $96 \%$ & $68 \%$ & 6.2 & $61 \%$ & $39 \%$ & 0.16 & 0.0 \\
\hline & opt & 0.88 & $95 \%$ & $74 \%$ & 1.6 & $96 \%$ & $68 \%$ & 2.1 & $87 \%$ & $48 \%$ & 2.7 & 0.11 \\
\hline
\end{tabular}

${ }^{\mathrm{a}}$ For LGM200 and LGM400, the upper row shows the first-guess values and the lower row shows the optimized values, respectively. The top row shows the original first-guess values (i.e., before the preparatory runs) for the SST.

FW1 $\sigma$ indices were well improved and perfectly met the requirements, although the optimized cost was somewhat larger than 1. It is suggested that the synthesis of the $\delta^{18} \mathrm{O}$ data was basically successful but that the spread of model results around the corresponding data deviated from a perfect normal distribution.

On the other hand, the fit to the $\delta^{13} \mathrm{C}_{\text {calcite }}$ data was somewhat worse than for the SST and $\delta^{18} \mathrm{O}$. Although $J_{\mathrm{C} 13}^{\prime}$ was substantially reduced, it was still almost twice as large as required. Contrary to the $\delta^{18} \mathrm{O}$ case, the optimized FW $2 \sigma$ and FW $1 \sigma$ indices were also insufficient. Those three indicators became even worse during the first-guess run for LGM400, because a 200 year forward run was too short to reach a steady state and the remineralization factor $(\alpha)$ optimized for the 200 year run was not suitable for a 400 year run. During LGM400, however, the model-data misfits greatly improved. The optimized $J^{\prime}{ }_{13}$ of 2.1 corresponded to $0.29 \%$ in terms of a root-mean-square (RMS) of model-data discrepancies. Actually, if we took $\sigma=0.29 \%$ o to calculate FW $2 \sigma$ and $\mathrm{FW} 1 \sigma$, they became $98 \%$ and $72 \%$, respectively.

The $J_{S S H}^{\prime}$ value was dramatically reduced from its first guess in LGM200, but although the first-guess $J_{S S H}^{\prime}$ was below 1 in LGM400, the optimized value became larger than 1 in exchange for the improvement for $\delta^{13} \mathrm{C}$. However, it was still within the $2 \sigma$ range. $J_{\text {ctrl }}^{\prime}$ was well below 1 , showing that the magnitude of the control-variable adjustments was acceptable. Similarly to the modern case, to assure that the total adjustment of the control variables including the preparatory phase was not too large, we assessed the deviation from the original first-guess values taken from Merkel et al. [2010] (i.e., the values of $\mathbf{F}(i)$ before the preparatory runs). The normalized total adjustment was equal to 0.008 , which implied that the model required much smaller control-variable adjustments to meet the much scarcer data coverage (i.e., much weaker constraint) as compared to the modern state estimation.

\section{Reconstructed Tracer Fields}

The globally averaged difference of SST (LGM400 minus MOD400) was $-2.2 \mathrm{~K}$. As suggested by the normalized cost, the estimated global SST field in LGM400 was generally in good agreement with the MARGO paleodata (Figure 2a). Relatively larger differences were found in the upwelling regions along the west coasts of the South American and African continents probably caused by the poor representation of the coastal upwelling phenomenon in our coarse-resolution model. Compared to the reconstructed modern SST field in MOD400, the LGM SST was lower in most regions. In particular, it was colder by up to $10 \mathrm{~K}$ in the midlatitude $\left(30^{\circ}-60^{\circ}\right)$ bands of both hemispheres (Figure 2b). In some regions, however, the LGM SST was higher than the modern one. Most of the positive temperature anomalies along the latitude of $30^{\circ} \mathrm{S}$ are caused by the positive anomalies in the data themselves [MARGO Project Members et al., 2009; Annan and Hargreaves, 2013]. Also in the North Atlantic, there was one region with positive anomaly near data points from an alkenone-based SST reconstruction.

The RMS of model-data discrepancies for the modern $\delta^{18} \mathrm{O}_{\text {water }}$ was $0.24 \%$ and $0.25 \%$ o for the $\operatorname{LGM} \delta^{18} \mathrm{O}_{\text {calcite }}$. The reconstructed modern distribution of $\delta^{18} \mathrm{O}_{\text {water }}$ (Figure 3a) showed a water mass with positive $\delta^{18} \mathrm{O}_{\text {water }}$ values that can be identified with North Atlantic Deep Water (NADW) spreading southward up to $45^{\circ} \mathrm{S}$ at a depth of 2000-3000 m, while another water mass corresponding to Antarctic Intermediate Water penetrated northward to the equator at a depth of about $1000 \mathrm{~m}$. The optimized LGM $\delta^{18} \mathrm{O}_{\text {water }}$ distribution (Figure 3b) was obtained from the fitting the model to the $\delta^{18} \mathrm{O}_{\text {calcite }}$ data (Figure 3c). For a direct comparison to Figure 3a, 

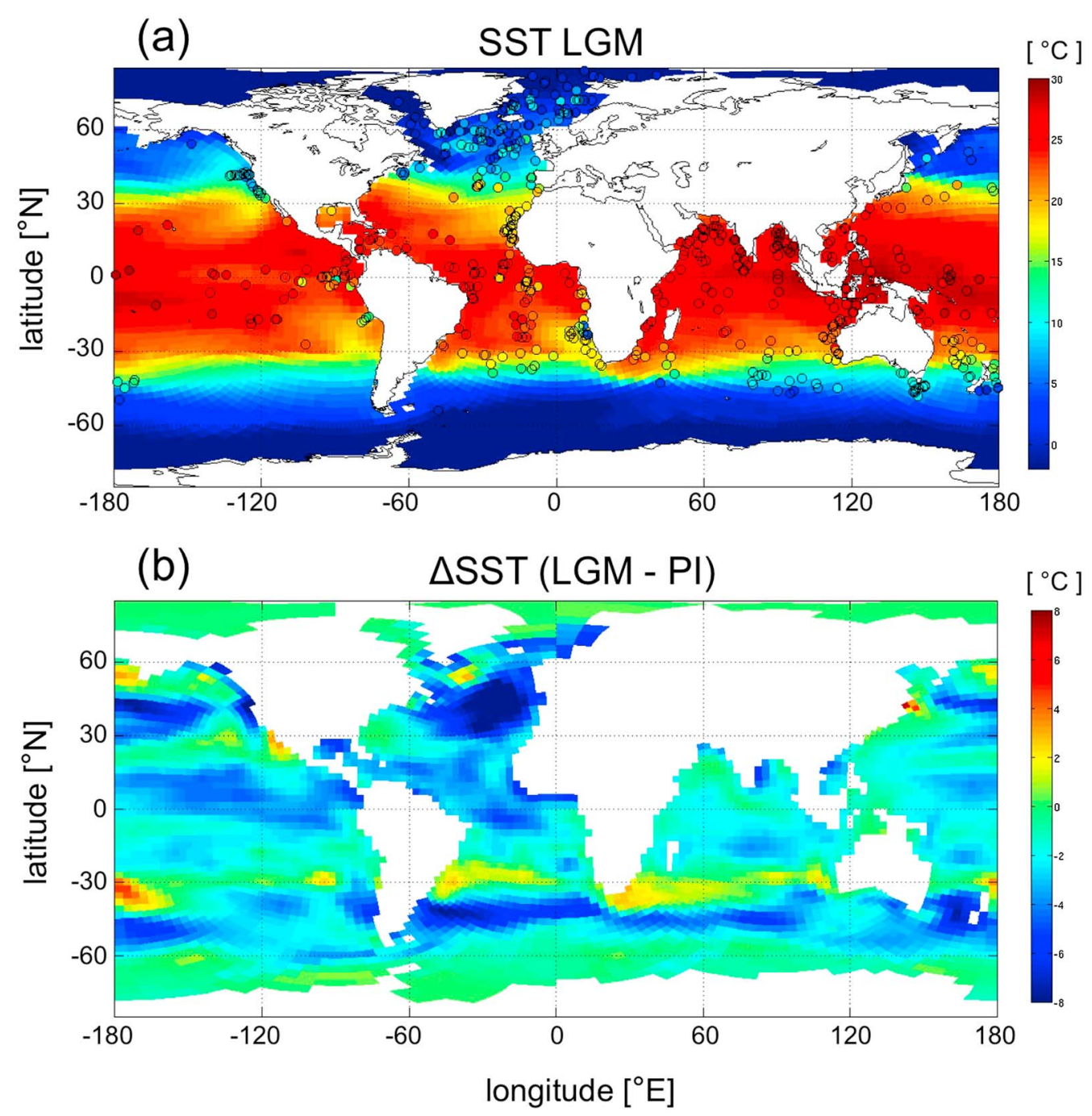

Figure 2. Estimated SST field in LGM400. (a) Comparison with the MARGO data shown as dots on the same color scale. (b) Difference from the modern SST obtained in MOD400.

the color scale was adjusted by taking the $1.1 \%$ offset into account (see section 4.3). In LGM400, the core of northern source deep water was shallower by $1000 \mathrm{~m}$ than in MOD400. The northward penetration of southern source water, on the other hand, was weaker both for the bottom water and for the intermediate water, suggesting stronger stratification of the Southern Ocean.

In MOD400, the estimated $\delta^{13} \mathrm{C}_{\mathrm{DIC}}$ field had an RMS of model-data discrepancies of $0.27 \%$, whereas that for $\delta^{13} C_{\text {calcite }}$ was $0.29 \%$ in LGM400. The optimized LGM $\delta^{13} C_{\text {DIC }}$ field (Figure $4 \mathrm{~b}$ ) was obtained from the fitting to the $\delta^{13} \mathrm{C}_{\text {calcite }}$ data (Figure 4c). The main deviations from the modern distribution included the southern source water having a very low end-member value, a larger vertical gradient in the depth range of 1000-5000 m, and a less pronounced tongue of northern source water.

A prominent discrepancy between the modern estimate and the data was the too low $\delta^{13} \mathrm{C}_{\mathrm{DIC}}$ in the bottom water of the estimate. A likely reason for this underestimation is the highly simplified remineralization model of equation (1) that assumed a homogeneous amount of remineralization. In reality, the amount of remineralization decreases with depth [e.g., Yamanaka and Tajika, 1996; Gebbie, 2014]. Because the remineralization releases isotopically depleted $\delta^{13} \mathrm{C}$ to the seawater, the assumption of homogeneous remineralization would indeed correspond to supplying too much low $\delta^{13} \mathrm{C}$ to the bottom water, hence causing too low $\delta^{13} \mathrm{C}_{\mathrm{DIC}}$ at such depths. In contrast to MOD400, the reconstructed LGM $\delta^{13} C_{\mathrm{DIC}}$ for the bottom water were not too light as compared to the reconstructions in spite of the same simplified remineralization model. One possible reason 

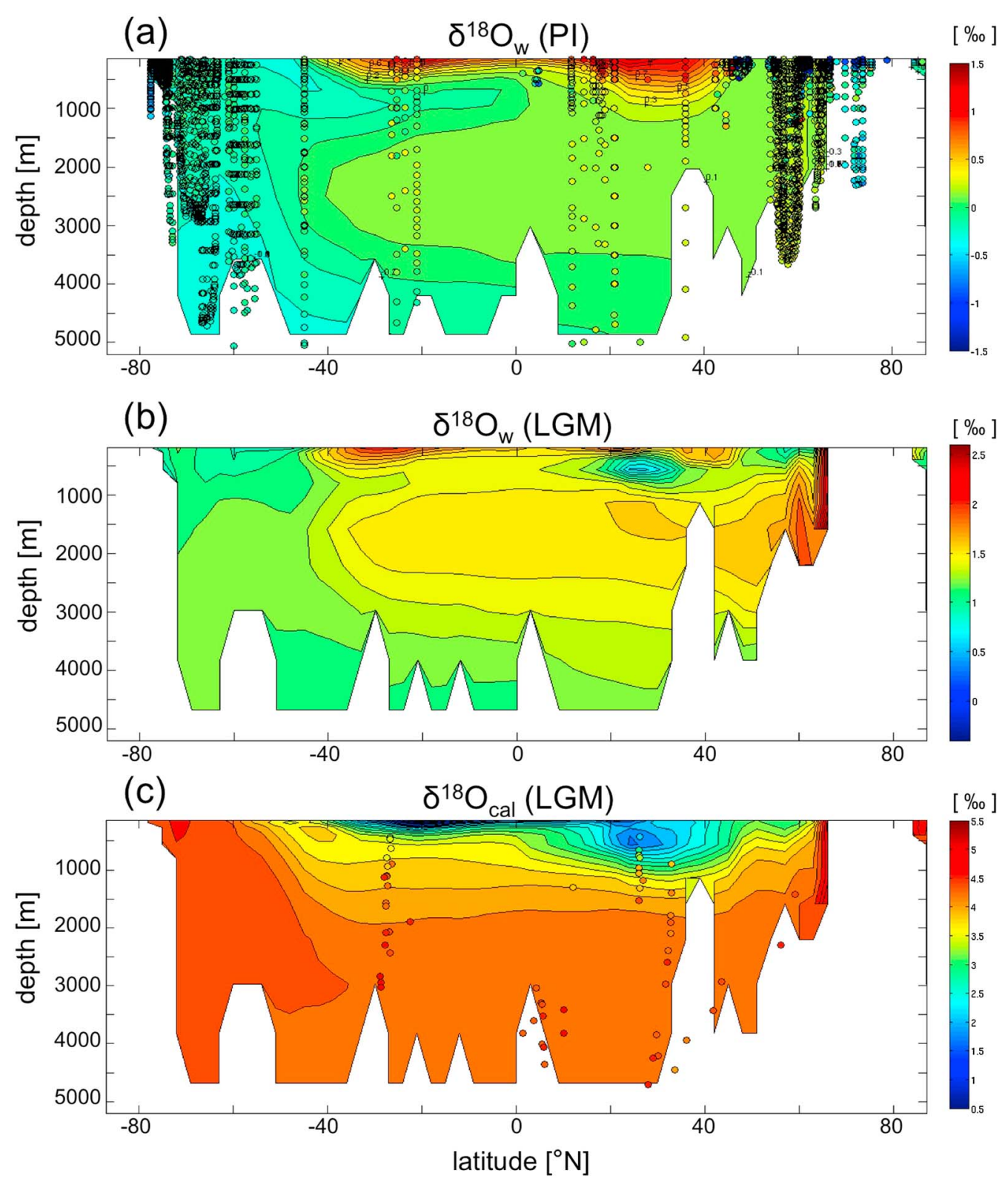

Figure 3. Estimated distribution of the oxygen isotopic composition shown as a meridional cross section at $32.5^{\circ} \mathrm{W}$. (a) $\delta^{18} \mathrm{O}_{\text {water }}$ in MOD400, (b) $\delta^{18} \mathrm{O}_{\text {water }}$ in LGM400, and (c) $\delta^{18} \mathrm{O}_{\text {calcite }}$ in LGM400. The dots indicate observations from the Atlantic west of $30^{\circ} \mathrm{W}$.

was that, for the LGM, there were only a few data points that constrained the shallower part (1000-2000 m) of the water column in the tropical region and the Southern Hemisphere and hence the model adjustment focused on the data in the bottom water.

\section{Reconstructed Circulation and Water Mass Distribution}

The volume transport of the AMOC in LGM400 as indicated by the maximum of the stream function (Figure 5) was 21.3 sverdrup $\left(\mathrm{Sv}, 10^{6} \mathrm{~m}^{3} / \mathrm{s}\right)$, which is $32 \%$ stronger than in MOD400. The rate of southward deep water export at the equator or at $30^{\circ} \mathrm{S}$ was also substantially larger in the LGM than in the modern case.

To visualize the distribution of water masses more clearly, a passive dye tracer was released at the sea surface in the high-latitude North Atlantic [cf. Gebbie, 2014] in additional forward model runs with the optimized atmospheric forcings and parameters obtained in MOD400 or LGM400. The concentration of the "dye" was 

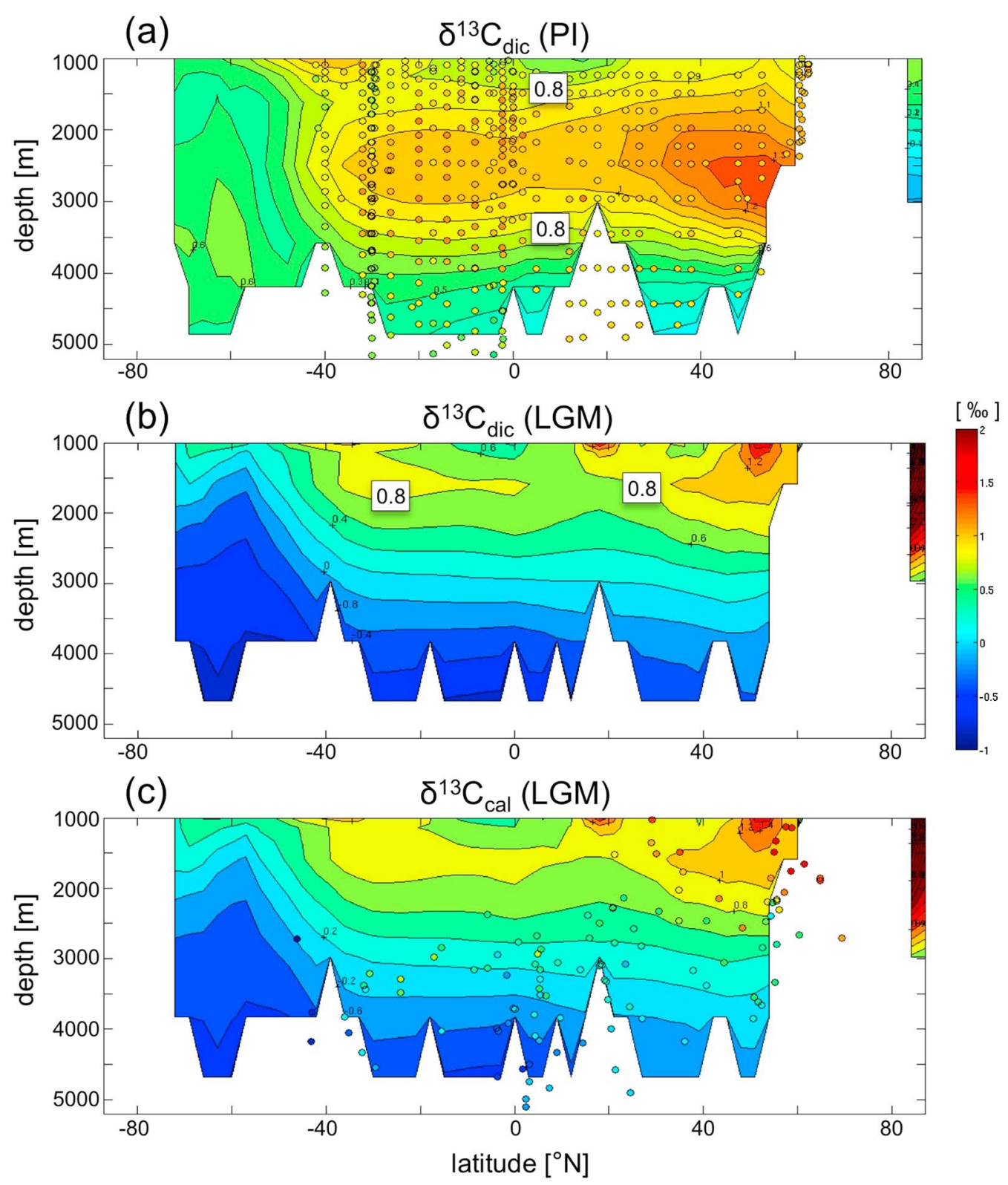

Figure 4. Estimated distribution of the carbon isotopic composition shown as a meridional cross section at $20^{\circ} \mathrm{W}$. (a) $\delta^{13} C_{\text {dic }}$ in MOD400, (b) $\delta^{13} C_{\text {dic }}$ in LGM400, and (c) $\delta^{13} C_{\text {calcite }}$ in LGM400. The dots indicate observations from the Atlantic between $10^{\circ} \mathrm{W}$ and $30^{\circ} \mathrm{W}$ for MOD400, and east of $30^{\circ} \mathrm{W}$ for LGM400.

fixed at 1 for every surface grid cell from $50^{\circ} \mathrm{N}$ to $80^{\circ} \mathrm{N}$ in the northern North Atlantic. To ensure a quasi-steady state of the tracer distribution, the model was run for 2000 model years by repeating the 400 year forcings five times.

The dye concentration showed that the northern source deep water occupied shallower depths in the LGM than in the modern case (Figure 6). In the modern case, the core of the northern source deep water was located at a depth of $\sim 2500 \mathrm{~m}$, while in the LGM case it was at a depth between 1500 and $2000 \mathrm{~m}$. Since the maximum of $\delta^{13} \mathrm{C}_{\mathrm{DIC}}$ was found in the same depth range (Figure $4 \mathrm{~b}$ ), this water mass may be identified with the ${ }^{13} \mathrm{C}$-rich intermediate water that was postulated by Duplessy et al. [1988] and Curry and Oppo [2005] and called Glacial North Atlantic Intermediate Water (GNAIW). Focusing on the 0.5 contour lines, the dye concentration would be larger than 0.5 between approximately 1000 and $4500 \mathrm{~m}$ in the modern case and between 1000 and $3500 \mathrm{~m}$ in the LGM case. 


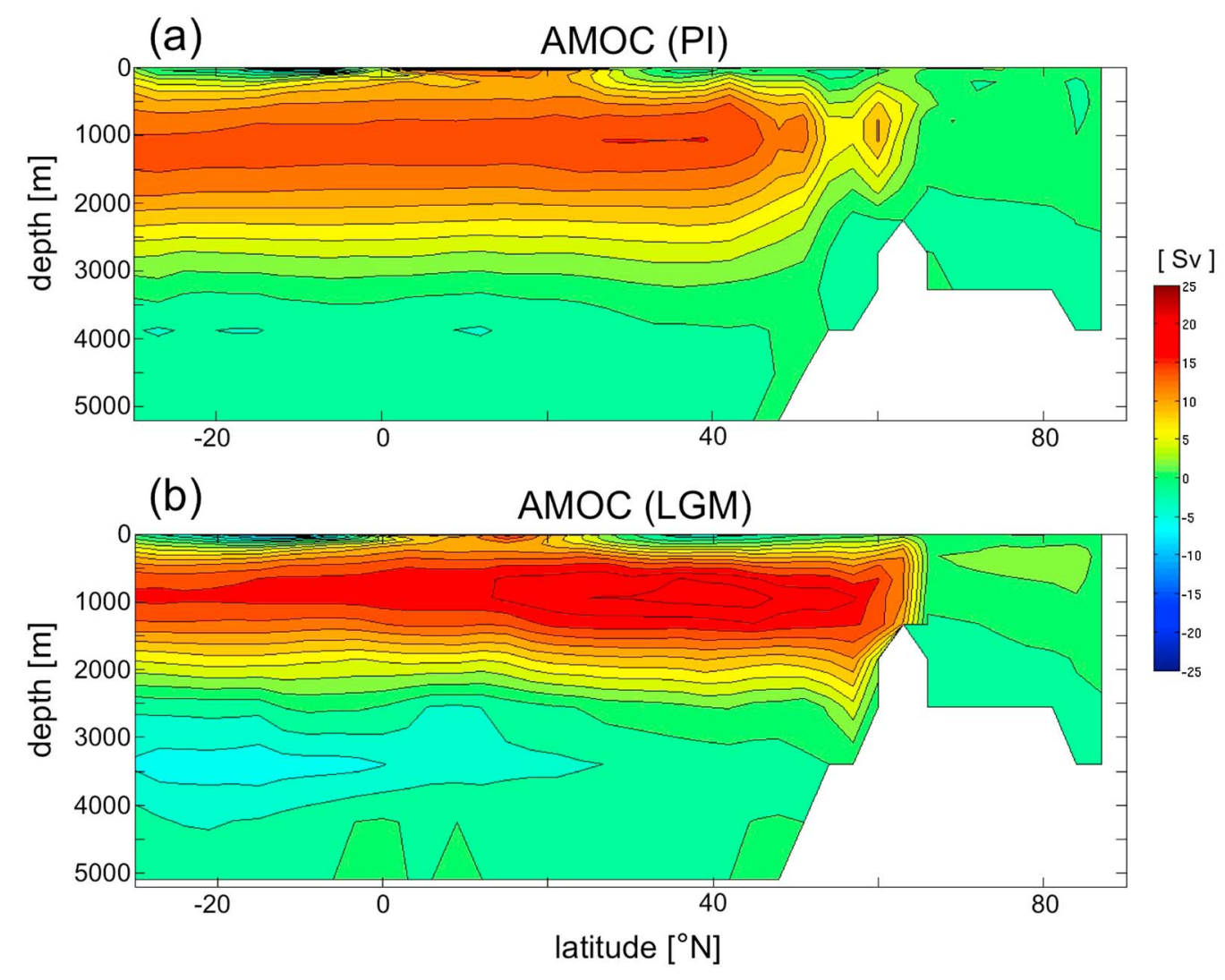

Figure 5. Stream function of the Atlantic Meridional Overturning Circulation (AMOC) calculated for (a) MOD400 and (b) LGM400. The maximum circulation rates of the equivalents of modern North Atlantic Deep Water (NADW) and modern Antarctic Bottom Water (AABW) cells were (a) $16.1 \mathrm{~Sv}$ and $-2.2 \mathrm{~Sv}$ and (b) 21.3 Sv and -5.3 Sv, respectively $\left(1 \mathrm{~Sv}=1.0 \times 10^{6} \mathrm{~m}^{3} / \mathrm{s}\right)$.

The shoaling of the northern source water also affected the upper ocean (depths shallower than $1000 \mathrm{~m}$ ). For example, while a dye concentration of 0.2 was observed at a depth of $700-1000 \mathrm{~m}$ in the modern case, it occurred at a depth of $500 \mathrm{~m}$ or even shallower in the LGM case. This feature would be consistent with a substantially weaker southern source intermediate water in the LGM case as indicated in Figures 3b and 4b.

Although the AMOC stream function showed a thicker and much stronger cell with anticlockwise circulation in the deepest part of the Atlantic (Figure 5), the dye concentration in the LGM bottom water was as high as in the modern bottom water $(0.3-0.4)$, which suggests that one cannot easily infer the relative contributions of northern and southern source water from the zonally integrated stream function only.

\section{Discussion}

\subsection{Comparison With Previous Studies}

\subsubsection{Sea-Surface Temperature}

The globally averaged SST difference between LGM400 and MOD400 was also consistent with the anomaly estimate by the Climate: Long-Range Investigation, Mapping, and Prediction (CLIMAP) project [Climap Project Members, 1976], although nowadays the CLIMAP anomaly is considered to be too small [e.g., Crowley, 2000].

By averaging over all $5^{\circ} \times 5^{\circ}$ grid cells that contain data, MARGO Project Members et al. [2009] estimated the globally averaged SST anomaly between the LGM and modern ocean as $(-1.9 \pm 1.8) \mathrm{K}$. The estimates based on our study (LGM400 minus MOD400) agreed with those by MARGO Project Members et al. [2009] within the error bars, for the global as well as the regional anomalies (Table 5). However, there seems to be a systematic difference in that our estimates tend to imply a slightly larger glacial cooling. This tendency was most pronounced in the tropics, where our estimate for the Pacific was statistically distinguishable from the MARGO estimate. In our case, the data assimilation scheme using an ocean general circulation model compensated for the sparseness of the data and provided for a physics-based method of interpolation and extrapolation. 

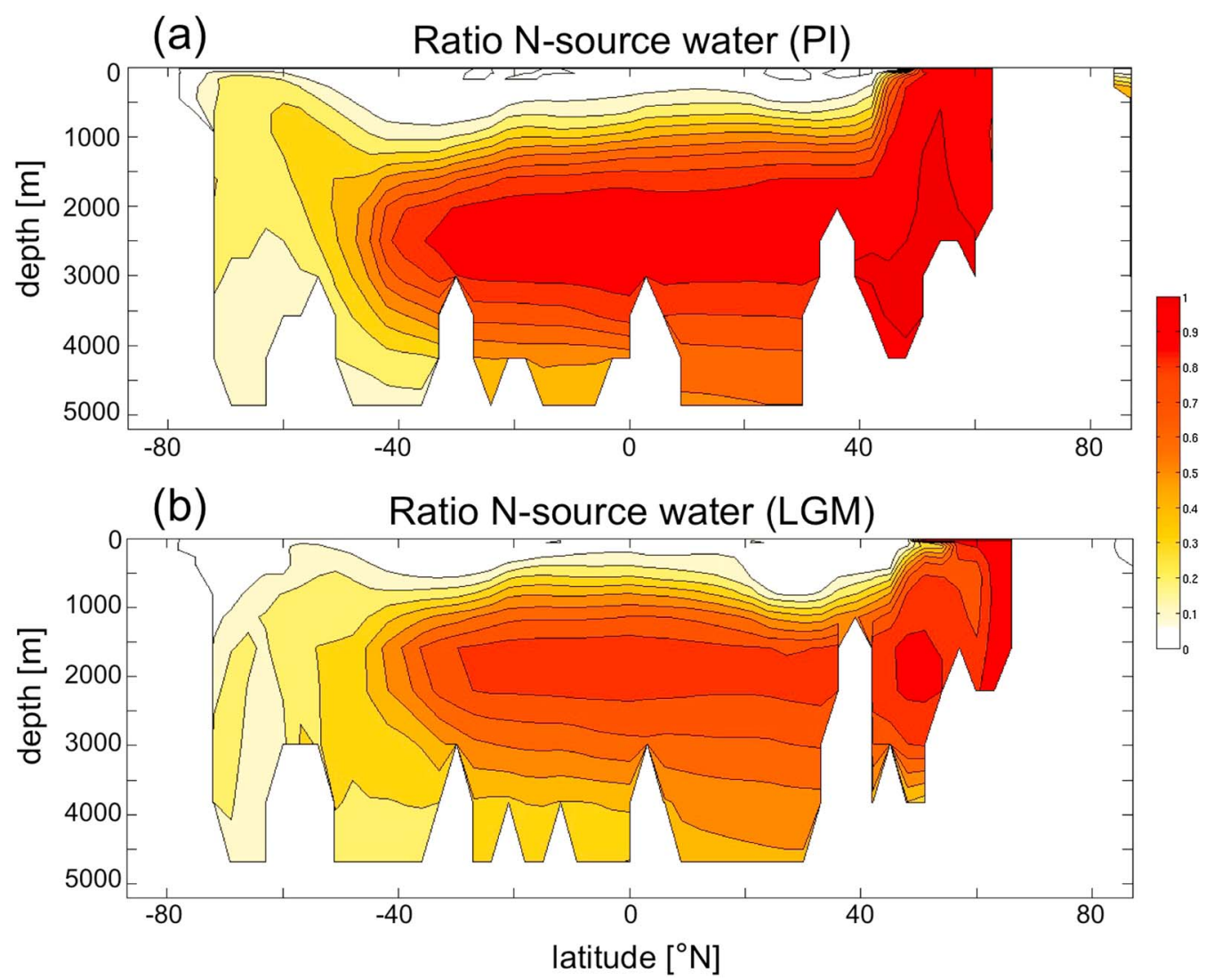

Figure 6. Concentration of northern source water obtained from the dye tracer experiments. Meridional cross sections at $35^{\circ} \mathrm{W}$ for (a) MOD400 and (b) LGM400.

In the case of MARGO Project Members et al. [2009], extrapolation into areas void of data was avoided on purpose, but as a consequence their estimates of the global and regional SST anomalies suffer from the low grid coverage (which is $\sim 20 \%$ for the global ocean).

The global mean anomaly of surface air temperature was $-5.8 \mathrm{~K}(-4.2 \mathrm{~K}$ over the ocean) in our estimates, which was somewhat larger than the recent estimate of $(-4.0 \pm 0.8) \mathrm{K}$ by Annan and Hargreaves [2013]. The corresponding anomaly for the first-guess forcing fields between the modern and LGM state estimation was already $-5.8 \mathrm{~K}$. This implies that the state estimation did not require large adjustments of surface air temperature in extensive areas to fit the model to the sparse ocean data.

\subsubsection{Isotopic Composition Fields}

The reconstructed modern distribution of $\delta^{18} \mathrm{O}_{\text {water }}$ (Figure 3a) showed a good agreement with a gridded data set based on regional $\delta^{18} \mathrm{O}$-salinity relationships and an objective interpolation method [LeGrande and Schmidt, 2006, Figure 2]. Because through the adjoint method our reconstruction was based on the physics of ocean dynamics, it did not suffer from the sharp discontinuities along regional boundaries that are unavoidable in the method devised by LeGrande and Schmidt [2006]. Instead, the constraint by model physics made it

Table 5. Regional Mean SST Anomalies (LGM-Modern) by the MARGO Project [MARGO Project Members et al., 2009] and This Study

\begin{tabular}{llcccc} 
Latitude Zone & Reference & Global & Atlantic & Indian & Pacific \\
\hline $90^{\circ} \mathrm{S}-90^{\circ} \mathrm{N}$ & MARGO & $-1.9 \pm 1.8 \mathrm{~K}$ & $-2.4 \pm 2.2 \mathrm{~K}$ & $-1.6 \pm 1.1 \mathrm{~K}$ & $-1.5 \pm 1.8 \mathrm{~K}$ \\
& This study & $-2.2 \mathrm{~K}$ & $-2.8 \mathrm{~K}$ & $-1.7 \mathrm{~K}$ & $-2.1 \mathrm{~K}$ \\
$15^{\circ} \mathrm{S}-15^{\circ} \mathrm{N}$ & MARGO & $-1.7 \pm 1.0 \mathrm{~K}$ & $-2.9 \pm 1.3 \mathrm{~K}$ & $-1.4 \pm 0.7 \mathrm{~K}$ & $-1.2 \pm 1.1 \mathrm{~K}$ \\
& This study & $-2.6 \mathrm{~K}$ & $-3.2 \mathrm{~K}$ & $-1.9 \mathrm{~K}$ & $-2.7 \mathrm{~K}$ \\
\hline
\end{tabular}




\begin{tabular}{|c|c|c|c|c|c|}
\hline \multicolumn{4}{|c|}{ Site Information } & \multirow{2}{*}{$\begin{array}{l}\text { Pore Water } \\
\delta^{18} \mathrm{O}_{\mathrm{w}}(\% \circ)\end{array}$} & \multirow{2}{*}{$\begin{array}{l}\text { LGM400 } \\
\delta^{18} \mathrm{O}_{\mathrm{w}}(\% 0)\end{array}$} \\
\hline ODP Site & Latitude & Longitude & Depth (m) & & \\
\hline 981 & $55^{\circ} \mathrm{N}$ & $14^{\circ} \mathrm{W}$ & 2184 & $1.05 \pm 0.1$ & 1.5 \\
\hline 1063 & $33^{\circ} \mathrm{N}$ & $57^{\circ} \mathrm{W}$ & 4584 & $0.75 \pm 0.1$ & 1.2 \\
\hline 1093 & $50^{\circ} \mathrm{S}$ & $6^{\circ} \mathrm{E}$ & 3626 & $1.17 \pm 0.1$ & 1.2 \\
\hline
\end{tabular}

more difficult for the model to fit the data. As a result, the RMS of model-data discrepancies in our estimates was somewhat larger than in the study by LeGrande and Schmidt [2006].

The reconstructed LGM $\delta^{18} \mathrm{O}_{\text {water }}$ could be directly compared with the oxygen-isotope composition of seawater restored from pore water samples from seafloor sediments [Adkins et al., 2002], although the $\delta^{18} \mathrm{O}_{\text {water }}$ may not be determined uniquely from the pore water [Wunsch, 2016]. Our result for the Southern Hemisphere (Ocean Drilling Program (ODP) site 1093) agrees with the pore water value within the errors, whereas our estimates for the Northern Hemisphere were considerably higher than the observations (Table 6). In the framework of this study, the assimilation of $\delta^{18} \mathrm{O}$ information was done in terms of $\delta^{18} \mathrm{O}_{\text {calcite }}$. Because $\delta^{18} \mathrm{O}_{\text {calcite }}$ depends on both $\delta^{18} \mathrm{O}_{\text {water }}$ and temperature of the ambient seawater, the $\delta^{18} \mathrm{O}_{\text {calcite }}$ information alone does not uniquely determine $\delta^{18} \mathrm{O}_{\text {water }}$. The comparison with the pore water observation implied that in LGM400 the model adjusted $\delta^{18} \mathrm{O}_{\text {water }}$ too much instead of adjusting seawater temperature, although that was the best estimate with respect to the chosen objective function. Another potential problem could be the limited length of the forward runs (400 year) that is still not long enough to advect the Northern Hemisphere information to the Southern Hemisphere [Wunsch and Heimbach, 2008]. Thus, the short integration time compared to the advective time scales of $\delta^{18} \mathrm{O}_{\text {water }}$ could have been compensated by unreasonably large adjustments of $\delta^{18} \mathrm{O}_{\text {water }}$ values in the Northern Hemisphere.

The reconstructed modern $\delta^{13} C_{\mathrm{DIC}}$ field was consistent with previous studies [Curry and Oppo, 2005; Schmittner et al., 2013; Gebbie, 2014] in the Atlantic (Figure 4a), at least with respect to the contour lines of $0.8 \%$ or $1.0 \%$ reaching up to $\sim 40^{\circ} \mathrm{S}$ at a depth of $2000-3000 \mathrm{~m}$. The $\mathrm{LGM} \delta^{13} \mathrm{C}_{\mathrm{DIC}}$ distribution also agreed in general with previous studies [Curry and Oppo, 2005; Brovkin et al., 2007; Gebbie, 2014]. We note again that our estimate was based on both the physical ocean dynamics and the available proxy data. Although the RMS of model-data discrepancies of $0.29 \%$ was somewhat larger than the assumed data uncertainty $(0.2 \%$ o), it was clearly smaller than the $0.68 \%$ o reported by Hesse et al. [2011], which demonstrates the beneficial effect of the data assimilation in the current study.

The reconstructed isotopic composition fields for the LGM were also compared with independent data compilations for the global ocean including the Pacific and Indian Oceans [Oliver et al., 2010; Peterson et al., 2014] (Figure 7). The $\delta^{18} \mathrm{O}$ data from the data sets are associated with large uncertainties in the dating up to $10 \mathrm{kyr}$ [Oliver et al., 2010]. Taking the Pacific and Indian Ocean data into account for the LGM400 results leads to $J^{\prime}{ }_{\mathrm{O} 18}=2.4$ and $J_{\mathrm{C} 13}^{\prime}=6.3$, which correspond to the RMS values of model-data differences of $0.31 \%$ and $0.50 \%$, respectively. These cost function values suggest that the reconstructed isotopic composition fields do not fit the observations within prior errors, even though the model-data misfits in the Pacific and Indian Oceans were slightly improved in the optimization that used only the Atlantic data. More precisely, on the one hand, the LGM400 $\delta^{13} \mathrm{C}$ field fit the measured $\delta^{13} \mathrm{C}$ values in the Indian Ocean reasonably well, because of a good first guess and because the Atlantic data lead to improvement in the Indian Ocean. On the other hand, the LGM400 $\delta^{18} \mathrm{O}$ values in the Pacific Ocean are systematically lower than the measured $\delta^{18} \mathrm{O}$ values of Oliver et al. [2010]. Our estimated $\delta^{13} \mathrm{C}$ values in LGM400 are also substantially lower (as much as 1\%o) at $3000 \mathrm{~m}$ in the Pacific Basin than the measured data.

A 400 year (forward) simulation is not long enough for signals from the Atlantic Ocean to reach all parts of the global ocean. This hypothesis was tested by running the model for 3000 extra years forward in time with the optimized forcings and parameters of LGM400. On the one hand, the longer integration clearly improved the negative bias for $\delta^{18} \mathrm{O}$ (Figures $7 \mathrm{c}$ and $7 \mathrm{~g}$ ), calling for an even longer adjoint-based state estimate. On the other hand, the 3000 year model run did not reduce the $\delta^{13} \mathrm{C}$ bias in most parts of the Pacific and Indian Oceans (Figures $7 \mathrm{~d}$ and $7 \mathrm{~h}$ ) to suggest that, even though signals from the Atlantic are allowed to propagate into the Pacific, the deep ocean circulation and remineralization processes in the Pacific cannot 
(a) $\delta^{18} \mathrm{O}_{\text {cal }}$ LGM400 @ $3000 \mathrm{~m}$

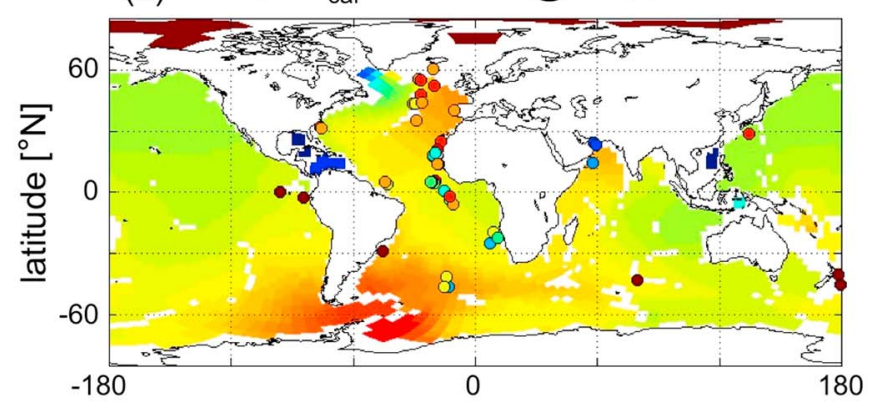

(c) $\quad \delta^{18} \mathrm{O}_{\text {cal }} 3000-y r$ run @ 3000 m

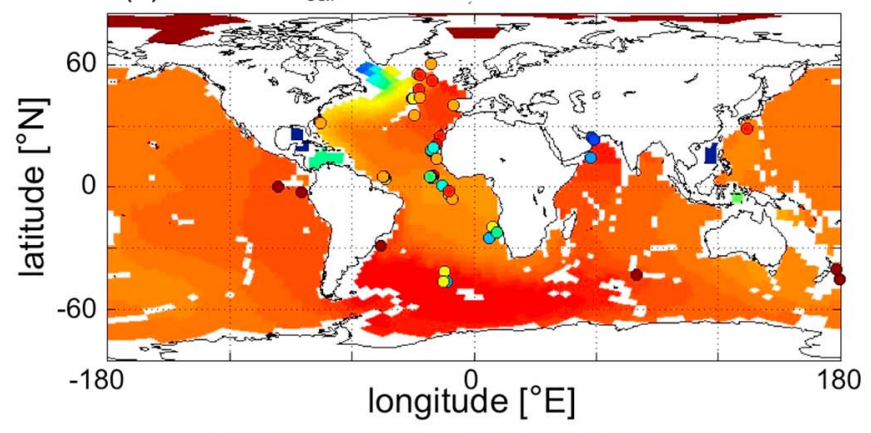

(b) $\quad \delta^{13} C_{\text {cal }}$ LGM400@3000 m

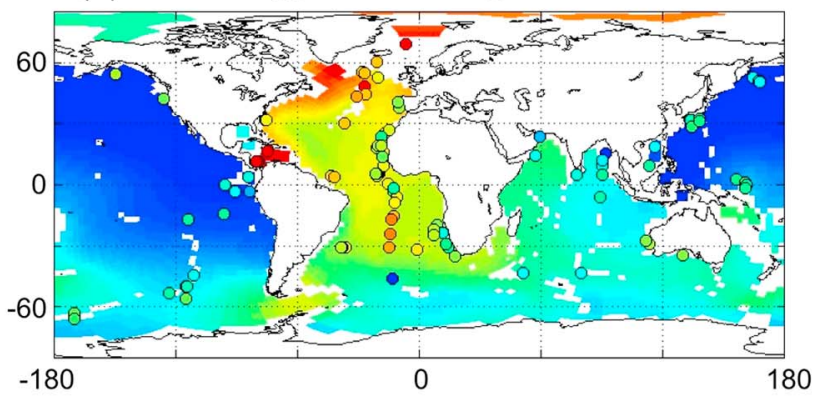

(d) $\quad \delta^{13} \mathrm{C}_{\text {cal }} 3000-\mathrm{yr}$ run @ $3000 \mathrm{~m}$
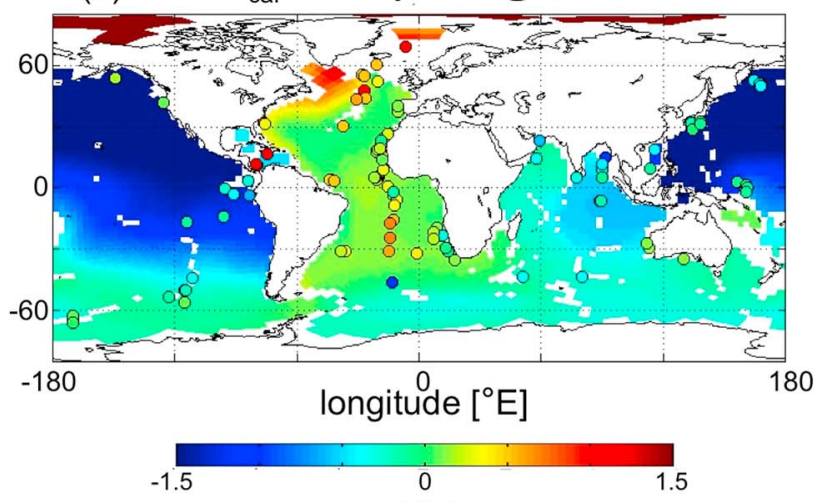

[\%o ]

(e) misfits for $\delta^{18} \mathrm{O}_{\text {cal }}$ LGM400@ 3000 m

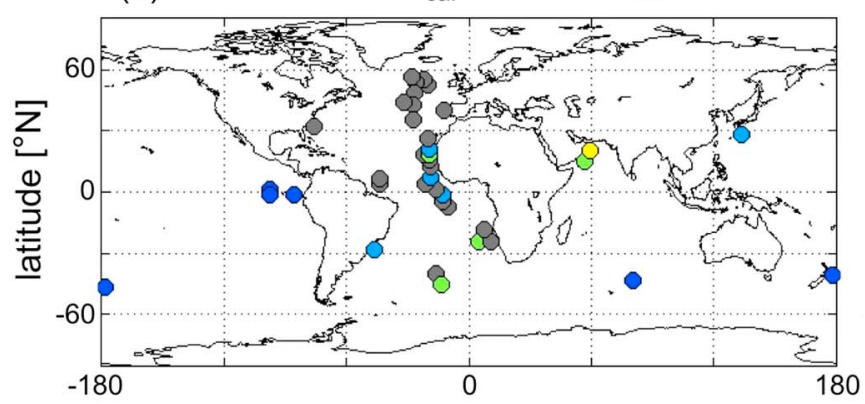

(g) misfits for $\delta^{18} \mathrm{O}_{\text {cal }} 3000-y r$ run @ 3000 m

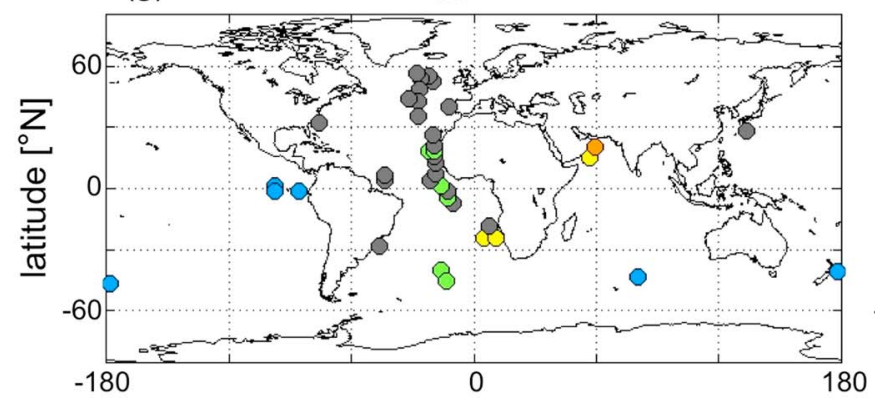

(f) misfits for $\delta^{13} C_{\text {cal }}$ LGM400@ 3000 m

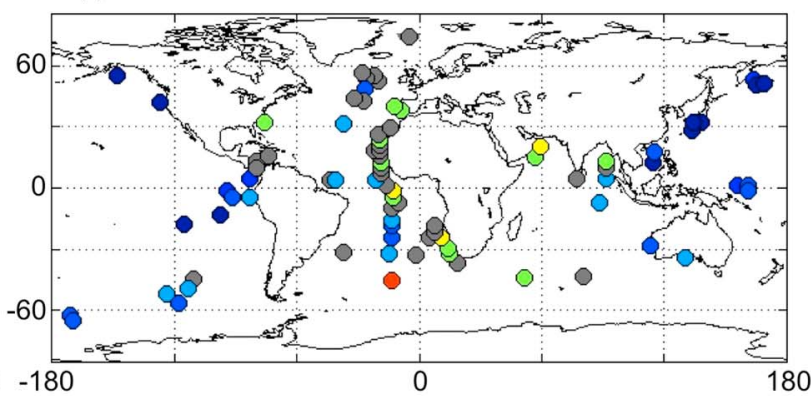

(h) misfits for $\delta^{13} C_{\text {cal }}$ 3000-yr run @ 3000 m

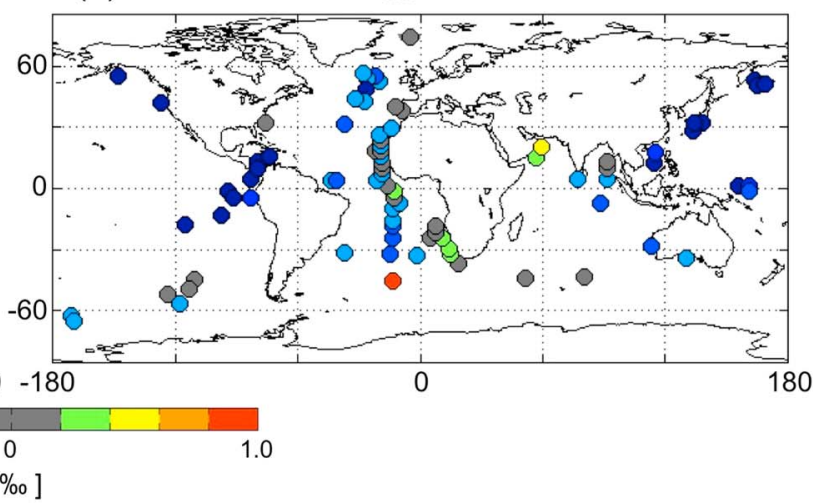

Figure 7. Reconstructed distributions of (a) $\delta^{18} \mathrm{O}_{\text {calcite }}$ and (b) $\delta^{13} \mathrm{C}_{\text {calcite }}$ at the depth of $3000 \mathrm{~m}$ in LGM400. The dots indicate observations including data in the Indian Ocean and Pacific. (c, d) Distributions after 3000 year model integration are also shown. (e-h) The differences between the reconstructions and observations are shown. Grid cells with differences smaller than $0.2 \%$ in magnitude (i.e., the assumed uncertainty) are depicted as gray in color. 
entirely be constrained by processes in the Atlantic. During the LGM, the water-mass structure and circulation in the deep Pacific Ocean may have been different from today because of deep-water formation in the North Pacific Ocean [e.g., Matsumoto et al., 2002; Herguera et al., 2010; Rae et al., 2014]. Such processes in the North Pacific Ocean would have been independent from the Atlantic Ocean and can only be constrained with a sufficient amount of local data. In the worst case, there is a considerable impact of North Pacific deep water on the global circulation, in which case our global state estimate would be very inaccurate in the absence of data to constrain the North Pacific Ocean locally. In future estimates, more Pacific data would be desirable, and a remineralization model that depends on the oceanographic provinces should be included to improve the model-data fit.

\subsubsection{Atlantic Meridional Overturning Circulation}

The stronger AMOC in LGM400 is in line with independent evidence from paleodata that were not assimilated in this study: ${ }^{231} \mathrm{~Pa} /{ }^{230} \mathrm{Th}$ isotope ratios [Yu et al., 1996; Lippold et al., 2012]; grain-size analysis of ocean sediments [McCave et al., 1995; Manighetti and McCave, 1995; McCave and Hall, 2006]; and combined Cd/Ca and $\delta^{13} \mathrm{C}$ measurements [Curry and Oppo, 2005]. In particular, the shoaled but more active overturning cell during the LGM is supported by combined proxies of the ${ }^{231} \mathrm{~Pa} /{ }^{230} \mathrm{Th}$ ratio and $\mathrm{Nd}$ isotopes [Lippold et al., 2016]. But there is also evidence that suggests that the LGM AMOC was weaker than today [e.g., Lynch-Stieglitz et al., 1999; Piotrowski et al., 2005; McManus et al., 2004; Negre et al., 2010]. Previous adjoint-based state estimations show a 30\% weaker AMOC [Winguth et al., 2000] or a strength similar to the modern value [Dail, 2012]. Apart from the remaining ambiguity of the $A M O C$ strength, the three adjoint-based studies agree on the change in depth of the overturning circulation cell. For example, in this study, a shoaling of the AMOC from $\sim 3500 \mathrm{~m}$ in MOD400 to $2500 \mathrm{~m}$ in LGM400 was observed. Such a shoaling of the AMOC is also observed in the results of Winguth et al. [2000] and Dail [2012]. Stammer et al. [2016] show time-mean AMOC stream functions from 1960 to 2007 by six different data assimilation projects. Although the time window is not identical to that of our modern state estimate, four out of the six reconstructions clearly have a deeper NADW cell than our LGM reconstruction, and another four of them have a significantly weaker strength of NADW transport.

The difference in maximum AMOC strength between MOD400 and LGM400 can be linked to the difference in average densities of two latitudinal strips $\left(50-55^{\circ} \mathrm{N}\right.$, and $\left.35-40^{\circ} \mathrm{S}\right)$ at middepth $(750 \mathrm{~m})$. The hemispheric density difference was $0.63 \mathrm{~kg} / \mathrm{m}^{3}$ in LGM400, while it was $0.45 \mathrm{~kg} / \mathrm{m}^{3}$ in MOD400, supporting the positive correlation between the AMOC strength and the meridional density gradient across the Atlantic as suggested by Rahmstorf [1996]. The larger north-south density gradient in LGM400 is due to the salinity difference as seen in Figure 8a. There are (at least) two mechanisms for that. First, the gyre circulation is stronger in LGM400 due to stronger wind stress. As a consequence, more salt is transported northward with the western boundary current in the North Atlantic, contributing denser water to the convection regions. This is consistent with Muglia and Schmittner [2015] who suggest that strengthened wind-driven northward salt transport into the North Atlantic contributes to the increase of surface-water density at high latitudes, leading to the stronger and deeper AMOC in LGM simulations with the Paleoclimate Model Intercomparison Project Phase 3 models. Second, in the reconstructed LGM ocean, a distinct positive anomaly of evaporation was found in the high-latitude North Atlantic because of a lower specific humidity and a slightly higher SST. It also contributes to the increase in the density of the surface water.

Another potential mechanism leading to stronger AMOC during the LGM is the intensification of the overturning by increased tidal mixing caused by the sea level drop [Wunsch, 2003; Egbert et al., 2004; Green et al., 2009; Schmittner et al., 2015]. Tidal energy, which at present is dissipated by friction on the shallow continental shelves, would during the LGM instead be dissipated in the deep ocean, because a substantial area of the continental shelves were exposed. For example, Schmittner et al. [2015] estimated that the global mean vertical diffusivity (used as input parameters to a climate model) during the LGM was more than 3 times larger than at present day. The prior vertical diffusivity was $3 \times 10^{-5} \mathrm{~m}^{2} / \mathrm{s}$ for all the experiments in our study, and rather small uncertainties were prescribed (Table 2) mostly because it aided stabilizing the searches for the optimum solution. The adjustment of the diffusivity was substantially smaller than the given uncertainty both for the modern and LGM state estimates, which suggested that the difference in ocean circulation resulted mostly from the different surface forcing fields. This result, however, does not necessarily lead to rejecting the hypothesis that a more vigorous vertical mixing affected the LGM ocean circulation. Instead, it suggests that a vertical diffusivity similar to the modern one is consistent with the LGM data and their uncertainty used in this study. 

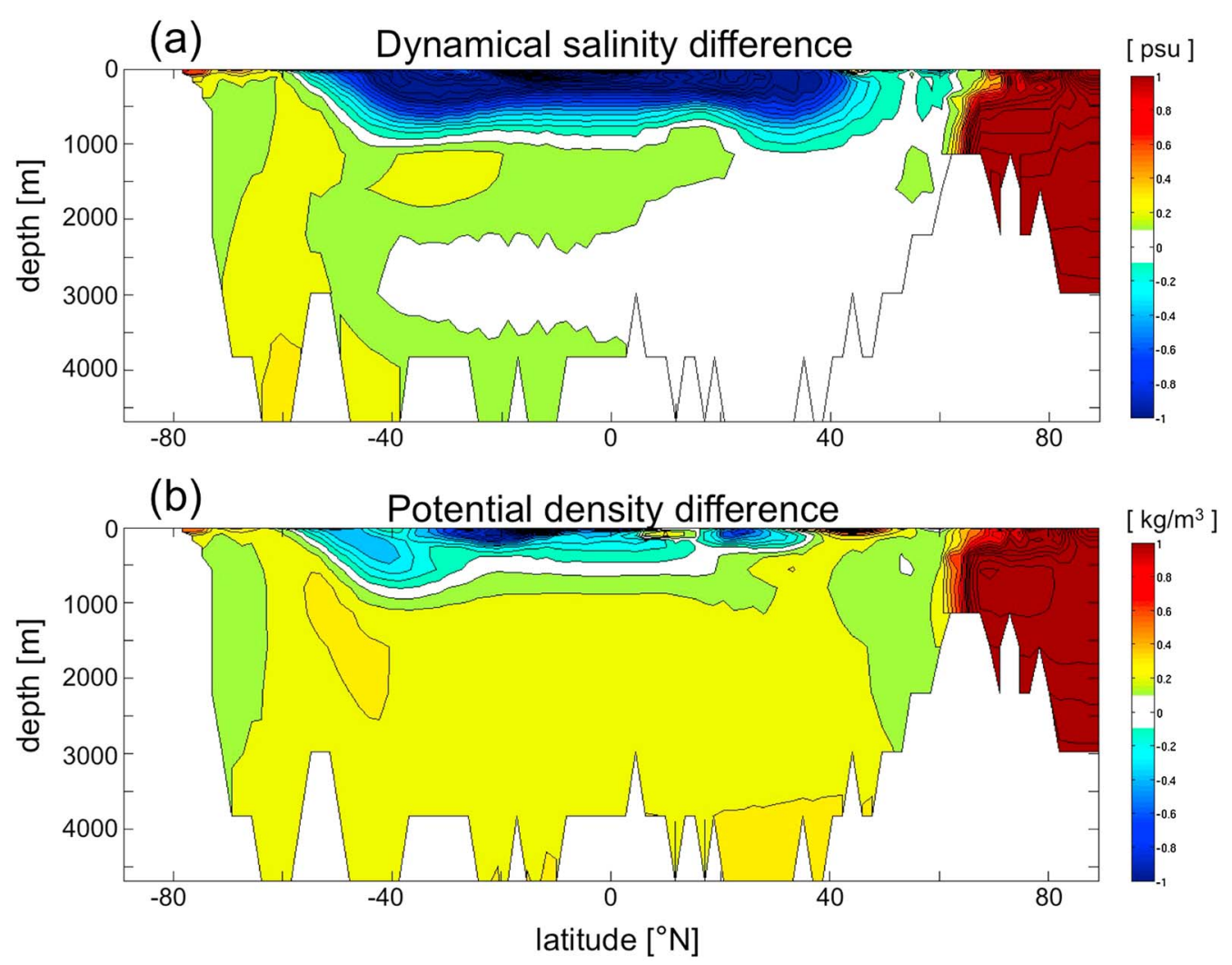

Figure 8. Atlantic zonal-mean differences (LGM400 - MOD400) for (a) salinity and (b) potential density. For both quantities, the global mean values were subtracted to remove the effects of a systematic difference and reveal the patterns of the difference.

We did another 200 year LGM state estimate with larger prior vertical diffusivities: $3 \times 10^{-5} \mathrm{~m}^{2} / \mathrm{s}$ for the depths shallower than $1500 \mathrm{~m}$ and $3 \times 10^{-4} \mathrm{~m}^{2} / \mathrm{s}$ for deeper depths. We obtained as good a cost reduction as in LGM200, with a maximum AMOC strength of $19.8 \mathrm{~Sv}$ and a similar depth to that for LGM400. The fit to the LGM data was equally good, suggesting that the vertical diffusivity cannot be constrained better with our method.

\subsection{Implication for the Atmospheric $p \mathrm{CO}_{2}$ Level}

The optimized remineralization factor $\alpha$ was 0.823 in MOD400 and 1.08 in LGM400, so $30 \%$ larger for the LGM. Using process-based biogeochemical models for the LGM, Bopp et al. [2003], Tagliabue et al. [2009], Oka et al. [2011], and Schmittner and Somes [2016] suggest a slightly (from several percent up to 10\%) lower export production during the LGM. Although those estimates are apparently in contradiction with ours, it should be noted that $\alpha$ meant the amount of remineralization in the ocean deeper than $1000 \mathrm{~m}$, which depends on the decomposition efficiency of organic matter as well as on the export production. Considering that the lower seawater temperature during the LGM would slow down the decomposition of organic matter [Matsumoto et al., 2007], the lower export production would be counteracted by the slower decomposition in the deep water.

On the other hand, the reconstructed ocean state in LGM400 was more stratified in salinity and density (Figure 8). Several lines of independent evidence support this result [Adkins et al., 2002; Insua et al., 2014], although a recent study suggests that salinity amplification in the abyss during the LGM is not necessarily constrained by the data [Wunsch, 2016]. A more stratified ocean would be consistent with a larger carbon storage in the deep ocean, which would contribute to a lower $p \mathrm{CO}_{2}$ in the atmosphere [e.g., Sigman and Boyle, 2000; Marchitto et al., 2007], in particular in conjunction with a larger volume of Antarctic Bottom Water (AABW) as shown in Brovkin et al. [2007].

Because our model did not include tracers such as $\mathrm{O}_{2}$ and ${ }^{14} \mathrm{C}$, we were not able to directly infer the ventilation rate of the deep ocean. However, the reconstructed LGM $\delta^{13} C_{D I C}$ having a larger vertical gradient of concentration especially in the Southern Ocean (Figure 4) suggested a more isolated very deep or bottom 
water mass. This reduced ventilation combined with the increased remineralization could contribute to the lower atmospheric $p \mathrm{CO}_{2}$ during the LGM.

However, the higher AABW production rates estimated for the LGM that are implied by the maximum circulation rate (Figure 5) may not support a $p \mathrm{CO}_{2}$ drawdown hypothesis [De Boer and Hogg, 2014]. In fact, a reduction of the AABW production rate during the LGM was suggested to be able to account for the drawdown of $p \mathrm{CO}_{2}$ [Toggweiler et al., 2006; De Boer et al., 2010]. Burke and Robinson [2012] argue that the observed depletion of radiocarbon in the Southern Ocean is consistent with a reduced deep-ocean ventilation during the LGM via the Southern Ocean and suggest that carbon in the deep ocean was more isolated from the atmosphere than in modern days. On the other hand, the glacial water mass geometry reconstructed from geochemical tracers indicates that the southern source water mass occupied a larger volume fraction of deep water than today [e.g., Duplessy et al., 1988; Curry and Oppo, 2005]. Therefore, larger deep-water volumes of southern origin produced at a slower rate would be required for a consistent $p \mathrm{CO}_{2}$ drawdown scenario, which implies that reduced vertical mixing between $A A B W$ and the northern source water mass would be required [De Boer and Hogg, 2014]. Reduced vertical mixing is also suggested by Lund et al. [2011] from the viewpoint of $\delta^{18} \mathrm{O}$ distribution. Moreover, if the diapycnal mixing between NADW and AABW was smaller during the LGM, then the $\mathrm{CO}_{2}$ may be favorably sequestered in the abyssal ocean [cf., Stephens and Keeling, 2000; Ferrari et al., 2014]. On the other hand, more tidal energy input to the deep ocean would contribute to an overall increase in vertical mixing as discussed in section 8.1.3 [Wunsch, 2003; Egbert et al., 2004; Green et al., 2009; Schmittner et al., 2015]. The actual magnitude of vertical mixing and its effect on the deep- and bottom-water ventilation are expected to depend on the distribution of water masses and their relative position to the bottom topography [Lund et al., 2011; Ferrari et al., 2014]. Therefore, in order to better contribute to the question of ventilation rates, one needs to determine the changes in spatial patterns of vertical mixing during the LGM by estimating the three-dimensional distribution of vertical diffusivity. Our method appears to be very well suited to address this question, but as mentioned in section 8.1.3, the vertical diffusivity was not well constrained by the available data.

\subsection{Uncertainty of the Estimates}

The adjoint-based state estimate provides a solution that is physically plausible and consistent with the assumed cost function and probability distribution. In the case of the LGM state estimate, the number of data was much smaller than the number of control variables of the model. Such mathematically underdetermined problems are ill posed and do not have a unique solution, but our regularization term $J_{\text {ctrl }}$ resolves the issue at the cost of introducing a bias toward the first guess. The reconstructed LGM ocean in LGM400 was similar to the first guess by CCSM3 [Merkel et al., 2010] with regard to the depth of NADW cell and the strength of AABW cell but was distinct with regard to the maximum strength of NADW cell (21.3 Sv in LGM400 versus 12 Sv with CCSM3). To determine the degree of dependency on the choice of first guess, we would need to carry out a series of state estimates using different first-guess fields. However, we can at least conclude that the LGM ocean reconstructed from the CCSM3 first guess is consistent with the data sets in this study.

Here we are interested in four other aspects of the uncertainty of the estimated ocean circulation and water-mass distribution: (1) variability or sensitivity around a single local minimum of the objective function; (2) uniqueness of the minimum, that is to say, the possible existence of a different, global minimum; (3) the possibility of a different shape of the objective function near the minimum that would result from perturbed data; and (4) systematic model errors. Item (4) is beyond the scope of this paper, as it would require at least one more adjoint OGCM. For items (2) or (3), we would need a large number of additional adjoint simulations, which would be computationally too expensive. However, we were able to infer the uncertainty caused by item (1) as follows.

We conducted several forward runs with random noise added to the optimized atmospheric forcings from LGM400. The noise was normally distributed with the following standard deviation: $1 \%$ for the air temperature $(\sim 3 \mathrm{~K})$ and $5 \%$ for other forcing fields. We prepared five sets of perturbed forcing fields to carry out five runs. The maximum AMOC strength in those runs was $21.3 \mathrm{~Sv}, 20.0 \mathrm{~Sv}, 20.4 \mathrm{~Sv}, 21.3 \mathrm{~Sv}$, and 21.0 Sv, and in all runs the depth of the GNAIW circulation cell was as shallow as in LGM400. The model-data misfits for the perturbed runs were naturally somewhat worse (several percent larger) than the best estimate. These experiments give us some confidence that the estimated ocean state in LGM400 was sufficiently robust from the viewpoint of the sensitivity around the local minimum of the objective function. 


\section{Conclusions}

Aiming at a physically plausible and reliable reconstruction of the LGM ocean state, an adjoint-based state estimation framework was developed based on state-of-the-art numerical models and proxy data. The framework enabled us to make maximal use of the available knowledge and data in an objective way and carry out the longest LGM adjoint simulations to date. The model-data misfit as formulated in terms of the objective function was successfully minimized in order to provide an LGM ocean state supported both by ocean dynamics and observations. This suggests that the various proxy data of different origin were compatible with each other within their uncertainties in the sense that they could be tied together by the physical and biogeochemical processes in the model. Compared to the modern ocean state estimated with the same method, the reconstructed LGM ocean state was characterized by a larger rate of the AMOC, a northern source intermediate water mass GNAIW shallower than the present-day NADW by $500-1000 \mathrm{~m}$ and a stronger stratification with more saline deep water. It is noted that the shallower GNAIW did not imply a weaker influence of northern source deep water on the bottom water of the Atlantic. The state estimation also provided a continuous global mapping of the sea surface temperature based on model physics.

The main problem of any LGM state estimation to date is the vast imbalance between the number of observations and the number of control variables and thus the very large number of degrees of freedom. Naturally, increasing the number of independent observations as much as possible would be the most straightforward way to mitigate this difficulty. Otherwise, more prior knowledge would need to be added by, for example, re-arranging the control variable space or adding more model physics. In a feasible next step, the cost function could be extended to include seasonal surface temperature fields [cf., Paul and Losch, 2012] to take full advantage of seasonal SST reconstructions provided by the MARGO project as well as by other studies [Benz et al., 2016]. Another desirable and potentially very important next step is obtaining sufficient data in the Pacific Ocean to include them in the state estimation framework. These data constrain the Pacific Ocean state better and would help to evaluate hypotheses about ocean circulation patterns in the Pacific Ocean during the LGM, which would in turn shed light on the role of the Pacific Ocean in large-scale climate variability.

\section{Appendix A: State Estimation for the Modern Ocean With the Original Data Sets}

Prior to the state estimations for the modern day described in the main text (i.e., MOD200 and MOD400), we had done another series of modern state estimation without the three countermeasures to avoid unreasonable atmospheric forcing fields in the optimized states (section 4.2). In addition to that, there were a few alterations; the first-guess initial and boundary conditions of $\delta^{18} \mathrm{O}_{\text {water }}$ for the 200 year estimation were taken from LeGrande and Schmidt [2006]. For $\delta^{13} \mathrm{C}_{\mathrm{DIC}}$, they were prepared by interpolating the discrete observations collected by [Schmittner et al., 2013] using Data-Interpolating Variational Analysis (DIVA) [Troupin et al., 2012]. Otherwise, we used the same configurations as used for MOD200 and MOD400.

The results of the preceding state estimations (hereafter, called MOD200org and MOD400org) are summarized in Table A1. Judging from $J^{\prime}$, FW2 $\sigma$, and FW $1 \sigma$, no excessive differences were observed between the optimized ocean state in MOD400org and that in MOD400 (Table 3). The reconstructed ocean circulation had 16.4 Sv of the maximum AMOC strength and $-2.5 \mathrm{~Sv}$ of the bottom circulation with AABW, which were also similar to those in MOD400. The reconstructed ocean had a stronger stratification with more saline deep water, too.

The resultant modified atmospheric forcings, however, showed remarkable discrepancies. In MOD400org, the bulk assessment of the deviation of modified atmospheric forcings from the first guess $\left(J_{\text {ctrl }}^{\prime}\right)$ showed the acceptable magnitudes of modification to them; besides, the normalized total adjustments that assess the

Table A1. Development of the Objective Function (the Normalized Costs $J^{\prime}$ ), the Fraction Within $2 \sigma$ (FW2 $\sigma$ ), and That Within $1 \sigma$ (FW1 $\sigma$ ) for the Modern State Estimates With the Original Data Sets

\begin{tabular}{|c|c|c|c|c|c|c|c|c|c|c|c|c|c|c|c|}
\hline & & \multicolumn{3}{|c|}{$\mathrm{T}$} & \multicolumn{3}{|c|}{$S$} & \multicolumn{3}{|c|}{$\delta^{18} \mathrm{O}$} & \multicolumn{3}{|c|}{$\delta^{13} \mathrm{C}$} & \multirow[b]{2}{*}{$J_{\mathrm{SSH}}^{\prime}$} & \multirow[b]{2}{*}{$J_{\mathrm{ctrl}}^{\prime}$} \\
\hline & & $J_{\mathrm{T}}^{\prime}$ & $\mathrm{FW} 2 \sigma$ & $\overline{\mathrm{FW} 1 \sigma}$ & $J_{S}^{\prime}$ & $\mathrm{FW} 2 \sigma$ & $\overline{\mathrm{FW} 1 \sigma}$ & $J_{\mathrm{O} 18}^{\prime}$ & $\mathrm{FW} 2 \sigma$ & $\mathrm{FW} 1 \sigma$ & $J_{C 13}^{\prime}$ & FW2 $\sigma$ & $\mathrm{FW} 1 \sigma$ & & \\
\hline \multicolumn{2}{|c|}{ Original First Guess } & 3.6 & $78 \%$ & $47 \%$ & 37 & $65 \%$ & $43 \%$ & & & & & & & & \\
\hline \multirow[t]{2}{*}{ MOD200org } & $1 \mathrm{st}$ & 1.6 & $93 \%$ & $55 \%$ & 4.3 & $79 \%$ & $71 \%$ & 4.2 & $84 \%$ & $73 \%$ & 0.97 & $96 \%$ & $68 \%$ & $1.9 \times 10^{7}$ & 0.0 \\
\hline & opt & 1.5 & $94 \%$ & $71 \%$ & 2.5 & $90 \%$ & $70 \%$ & 1.7 & $95 \%$ & $85 \%$ & 0.49 & $99 \%$ & $86 \%$ & 0.30 & 0.018 \\
\hline \multirow[t]{2}{*}{ MOD400org } & 1st & 1.8 & $93 \%$ & $59 \%$ & 3.0 & $86 \%$ & $63 \%$ & 1.7 & $95 \%$ & $85 \%$ & 0.95 & $96 \%$ & $71 \%$ & $4.5 \times 10^{7}$ & 0.0 \\
\hline & opt & 1.8 & $93 \%$ & $59 \%$ & 2.5 & $90 \%$ & $69 \%$ & 1.6 & $95 \%$ & $85 \%$ & 1.2 & $92 \%$ & $64 \%$ & 0.013 & $1.3 \times 10^{-3}$ \\
\hline
\end{tabular}


(a) Original

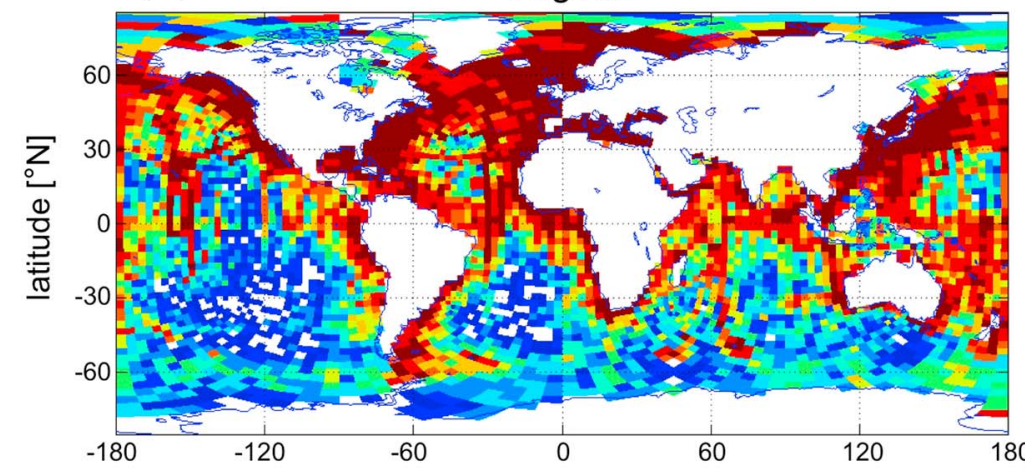

(b)

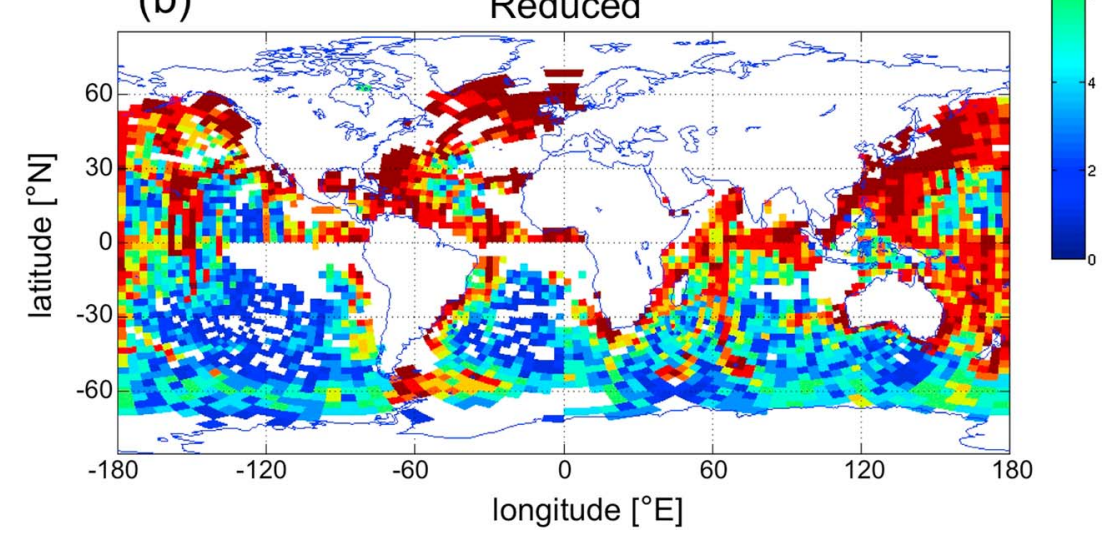

Figure A1. Locations of monthly SST data for the modern state estimate: (a) the original data sets and (b) the reduced data sets. The value shows the number of months that have data.

deviation from the original first-guess values were 1.4, which indicated that the adjustments were in a reasonable range. Nevertheless, the adjusted atmospheric forcing fields were found physically unreasonable in some regions.

If we defined the regions of unreasonable adjustments as grid cells that had any of the following: airtemperature adjustment larger than $40 \mathrm{~K}$, negative precipitation, negative specific humidity, or negative downward shortwave radiation, typically they are coastal areas including the upwelling regions along the west coasts of continents, "tongues" in the tropical Pacific and Atlantic affected by the equatorial upwelling processes, the Arctic regions, and comparatively closed (i.e., with insufficient communication with the open ocean) seas. It implied that the model has significant bias in such regions caused by, for example, the poor representation of the coastal upwelling processes due to the coarse resolution of model, so that, to compensate for the model deficit, the model input needed to be modified to realize a good match to the observation. From this point of view, MOD400org was not consistent with plausible reconstructed atmospheric conditions, although it succeeded in providing continuous tracer distributions that are consistent with as much data as available.

The authors would like to thank Andreas Schmittner and Karen Kohfeld for their insightful comments and suggestions. All data for this paper are properly cited and referred to in the reference list. This research was funded by the DFG-Research Center/Center of Excellence MARUM - "The Ocean in the Earth System" (www.marum.de; FKZ: EXC 309) as well as the project PalMod (www.palmod.de; FKZ: 01LP1505D) within the framework of Research for Sustainable Development (FONA, http://fona.de) by the German Federal Ministry for Education and Research (BMBF). The adjoint model was generated using TAF [Giering and Kaminski, 1998].

To avoid this problem and to give priority to plausible atmospheric forcings, we excluded the regions of unreasonable adjustments from the domain of model-data comparison regarding the physical tracers for the main state estimations for modern days (see section 4.2), thereby minimizing the emergence of outliers in modified forcing fields. The data coverage before and after the data reduction is shown in Figure A1.

\section{References}

Adcroft, A., J.-M. Campin, C. Hill, and J. Marshall (2004), Implementation of an Atmosphere Ocean General Circulation Model on the Expanded Spherical Cube, Mon. Weather Rev., 132, 2845-2863, doi:10.1175/MWR2823.1.

Adkins, J. F., and D. P. Schrag (2001), Pore fluid constraints on deep ocean temperature and salinity during the Last Glacial Maximum, Geophys. Res. Lett., 28, 771-774, doi:10.1029/2000GL011597.

Adkins, J. F., K. Mclntyre, and D. P. Schrag (2002), The salinity, temperature, and $\delta^{18} \mathrm{O}$ of the glacial deep ocean, Science, 298, 1769-1773, doi:10.1126/science.1076252. 
Annan, J. D., and J. C. Hargreaves (2013), A new global reconstruction of temperature changes at the Last Glacial Maximum, Clim. Past, 9, 367-376, doi:10.5194/cp-9-367-2013.

Antonov, J. I., D. Seidov, T. P. Boyer, R. A. Locarnini, A. V. Mishonov, H. E. Garcia, O. K. Baranova, M. M. Zweng, and D. R. Johnson (2010), World ocean Atlas 2009, volume 2: Salinity, in NOAA Atlas NESDIS, vol. 69, edited by S. Levitus, pp. 1-184, U.S. Gov. Print. Off., Washington, D. C.

Benz, V., O. Esper, R. Gersonde, F. Lamy, and R. Tiedemann (2016), Last Glacial Maximum sea surface temperature and sea-ice extent in the Pacific sector of the Southern Ocean, Quat. Sci. Rev., 146, 216-237, doi:10.1016/j.quascirev.2016.06.006.

Bopp, L., K. E. Kohfeld, C. Le QuéRé, and O. Aumont (2003), Dust impact on marine biota and atmospheric $\mathrm{CO}_{2}$ during glacial periods, Paleoceanography, 18, 1046, doi:10.1029/2002PA000810.

Brovkin, V., A. Ganopolski, D. Archer, and S. Rahmstorf (2007), Lowering of glacial atmospheric $\mathrm{CO}_{2}$ in response to changes in oceanic circulation and marine biogeochemistry, Paleoceanography, 22, PA4202, doi:10.1029/2006PA001380.

Burke, A., and L. F. Robinson (2012), The southern ocean's role in carbon exchange during the last deglaciation, Science, 335, 557-561, doi:10.1126/science.1208163.

Burke, A., O. Marchal, L. I. Bradtmiller, J. F. McManus, and R. François (2011), Application of an inverse method to interpret ${ }^{231} \mathrm{~Pa} /{ }^{230} \mathrm{Th}$ observations from marine sediments, Paleoceanography, 26, PA1212, doi:10.1029/2010PA002022.

Climap Project Members (1976), The surface of the Ice-Age Earth, Science, 191, 1131-1137, doi:10.1126/science.191.4232.1131.

Crowley, T. J. (2000), CLIMAP SSTs re-revisited, Clim. Dyn., 16, 241-255, doi:10.1007/s003820050325.

Curry, W. B., and D. W. Oppo (2005), Glacial water mass geometry and the distribution of $\delta^{13} \mathrm{Cof}^{2} \mathrm{CO}{ }_{2}$ in the western Atlantic Ocean, Paleoceanography, 20, PA1017, doi:10.1029/2004PA001021.

Dail, H., and C. Wunsch (2014), Dynamical reconstruction of upper-ocean conditions in the Last Glacial Maximum Atlantic, J. Clim., 27, 807-823, doi:10.1175/JCLI-D-13-00211.1.

Dail, H. J. (2012), Atlantic ocean circulation at the Last Glacial Maximum: Inferences from data and models, PhD thesis, Massachusetts Institute of Technology, Massachusetts and the Woods Hole Oceanographic Inst., Mass.

De Boer, A. M., and A. M. Hogg (2014), Control of the glacial carbon budget by topographically induced mixing, Geophys. Res. Lett., 41, 4277-4284, doi:10.1002/2014GL059963.

De Boer, A. M., A. J. Watson, N. R. Edwards, and K. I. C. Oliver (2010), A multi-variable box model approach to the soft tissue carbon pump, Clim. Past, 6, 827-841, doi:10.5194/cp-6-827-2010.

Del Giorgio, P. A., and C. M. Duarte (2002), Respiration in the open ocean, Nature, 420, 379-384.

Duplessy, J. C., N. J. Shackleton, R. G. Fairbanks, L. Labeyrie, D. Oppo, and N. Kallel (1988), Deep water source variations during the last climatic cycle and their impact on the global deep water circulation, Paleoceanography, 3, 343-360, doi:10.1029/PA003i003p00343.

Duplessy, J.-C., L. Labeyrie, and C. Waelbroeck (2002), Constraints on the ocean oxygen isotopic enrichment between the Last Glacial Maximum and the Holocene: Paleoceanographic implications, Quat. Sci. Rev., 21, 315-330, doi:10.1016/S0277-3791(01)00107-X.

Egbert, G. D., R. D. Ray, and B. G. Bills (2004), Numerical modeling of the global semidiurnal tide in the present day and in the Last Glacial Maximum, J. Geophys. Res., 109, C03003, doi:10.1029/2003JC001973.

Errico, R. M. (1997), What Is an adjoint model?, Bull. Am. Meteorol. Soc., 78, 2577-2591, doi:10.1175/1520-0477(1997)078<2577:WIAAM>2.0.CO;2.

Ferrari, R., M. F. Jansen, J. F. Adkins, A. Burke, A. L. Stewart, and A. F. Thompson (2014), Antarctic sea ice control on ocean circulation in present and glacial climates, Proc. Natl. Acad. Sci. U.S.A., 111, 8753-8758, doi:10.1073/pnas.1323922111.

Forget, G., J.-M. Campin, P. Heimbach, C. N. Hill, R. M. Ponte, and C. Wunsch (2015), ECCO version 4: An integrated framework for non-linear inverse modeling and global ocean state estimation, Geosci. Model Dev., 8, 3071-3104, doi:10.5194/gmd-8-3071-2015.

Gebbie, G. (2014), How much did glacial North Atlantic water shoal?, Paleoceanography, 29, 190-209, doi:10.1002/2013PA002557.

Gebbie, G., and P. Huybers (2006), Meridional circulation during the Last Glacial Maximum explored through a combination of South Atlantic $\delta^{18}$ O observations and a geostrophic inverse model, Geochem. Geophys. Geosyst., 7, Q11 N07, doi:10.1029/2006GC001383.

Gent, P. R., and J. C. McWilliams (1990), Isopycnal mixing in ocean circulation models, J. Phys. Ocean., 20, 150-160, doi:10.1175/1520-0485(1990)020<0150:IMIOCM>2.0.CO;2.

Giering, R., and T. Kaminski (1998), Recipes for adjoint code construction, ACM Trans. Math. Softw., 24(4), 437-474, doi:10.1145/293686.293695.

Gilbert, J. C., and C. Lemaréchal (1989), Some numerical experiments with variable-storage quasi-Newton algorithms, Math. Program., 45(3), 407-435, doi:10.1007/BF01589113.

Goericke, R., and B. Fry (1994), Variations of marine plankton $\delta^{13} \mathrm{C}$ with latitude, temperature, and dissolved $\mathrm{CO}_{2}$ in the world ocean, Global Biogeochem. Cycles, 8, 85-90, doi:10.1029/93GB03272.

Gouretski, V., and K. Koltermann (2004), WOCE global hydrographic climatology, Tech. Rep. 35.

Green, J. A. M., C. L. Green, G. R. Bigg, T. P. Rippeth, J. D. Scourse, and K. Uehara (2009), Tidal mixing and the meridional overturning circulation from the Last Glacial Maximum, Geophys. Res. Lett., 36, L15603, doi:10.1029/2009GL039309.

Griffies, S. M., et al. (2009), Coordinated ocean-ice reference experiments (COREs), Ocean Modell., 26, 1-46, doi:10.1016/j.ocemod.2008.08.007.

Heimbach, P., C. Hill, and R. Giering (2005), An efficient exact adjoint of the parallel MIT General Circulation Model, generated via automatic differentiation, Future Gener. Comput. Syst., 21(8), 1356-1371, doi:10.1016/j.future.2004.11.010.

Herguera, J. C., T. Herbert, M. Kashgarian, and C. Charles (2010), Intermediate and deep water mass distribution in the Pacific during the Last Glacial Maximum inferred from oxygen and carbon stable isotopes, Quat. Sci. Rev., 29, 1228-1245, doi:10.1016/j.quascirev.2010.02.009.

Hesse, T., M. Butzin, T. Bickert, and G. Lohmann (2011), A model-data comparison of $\delta^{13} \mathrm{C}$ in the glacial Atlantic Ocean, Paleoceanography, 26, PA3220, doi:10.1029/2010PA002085.

Huybers, P., G. Gebbie, and O. Marchal (2007), Can paleoceanographic tracers constrain meridional circulation rates?, J. Phys. Oceanogr., 37, 394-407, doi:10.1175/JPO3018.1.

Insua, T. L., A. J. Spivack, D. Graham, S. D'Hondt, and K. Moran (2014), Reconstruction of Pacific Ocean bottom water salinity during the Last Glacial Maximum, Geophys. Res. Lett., 41, 2914-2920, doi:10.1002/2014GL059575.

Köhl, A. (2015), Evaluation of the GECCO2 ocean synthesis: Transports of volume, heat and freshwater in the Atlantic, Q. J. R. Meteorol. Soc., 141, 166-181, doi:10.1002/qj.2347.

Köhl, A., and D. Stammer (2008), Variability of the meridional overturning in the North Atlantic from the 50-year GECCO state estimation, J. Phys. Oceanogr., 38, 1913-1930, doi:10.1175/2008JPO3775.1.

Köhl, A., D. Stammer, and B. Cornuelle (2007), Interannual to decadal changes in the ECCO global synthesis, J. Phys. Oceanogr., 37, 313-337, doi:10.1175/JPO3014.1.

Kurahashi-Nakamura, T., M. Losch, and A. Paul (2014), Can sparse proxy data constrain the strength of the Atlantic meridional overturning circulation?, Geosci. Model Dev., 7, 419-432, doi:10.5194/gmd-7-419-2014. 
Kwon, E. Y., J. L. Sarmiento, J. R. Toggweiler, and T. Devries (2011), The control of atmospheric $\mathrm{pCO}_{2}$ by ocean ventilation change: The effect of the oceanic storage of biogenic carbon, Global Biogeochem. Cycles, 25, GB3026, doi:10.1029/2011GB004059.

Legrand, P., and C. Wunsch (1995), Constraints from paleotracer data on the North Atlantic circulation during the Last Glacial Maximum, Paleoceanography, 10, 1011-1045, doi:10.1029/95PA01455.

LeGrande, A. N., and G. A. Schmidt (2006), Global gridded data set of the oxygen isotopic composition in seawater, Geophys. Res. Lett., 33, L12604, doi:10.1029/2006GL026011.

Levitus, S. E. (1982), Climatological Atlas of the World Ocean, NOAA Professional Paper 13, 173 pp., US U.S. Gov. Print. Off., Washington, D. C.

Lippold, J., Y. Luo, R. Francois, S. E. Allen, J. Gherardi, S. Pichat, B. Hickey, and H. Schulz (2012), Strength and geometry of the glacial Atlantic Meridional Overturning Circulation, Nat. Geosci., 5, 813-816, doi:10.1038/ngeo1608.

Lippold, J., et al. (2016), Deep water provenance and dynamics of the (de)glacial Atlantic Meridional Overturning Circulation, Earth Planet. Sci. Lett., 445, 68-78, doi:10.1016/j.epsl.2016.04.013.

Locarnini, R. A., A. V. Mishonov, J. I. Antonov, T. P. Boyer, H. E. Garcia, O. K. Baranova, M. M. Zweng, and D. R. Johnson (2010), World ocean Atlas 2009, volume 1: Temperature, in NOAA Atlas NESDIS, vol. 68, edited by S. Levitus, pp. 1-184, U.S. U.S. Gov. Print. Off., Washington, D. C.

Losch, M., D. Menemenlis, J.-M. Campin, P. Heimbach, and C. Hill (2010), On the formulation of sea-ice models. Part 1: Effects of different solver implementations and parameterizations, Ocean Modell., 33, 129-144, doi:10.1016/j.ocemod.2009.12.008.

Lund, D. C., J. F. Adkins, and R. Ferrari (2011), Abyssal Atlantic circulation during the Last Glacial Maximum: Constraining the ratio between transport and vertical mixing, Paleoceanography, 26, PA1213, doi:10.1029/2010PA001938.

Lynch-Stieglitz, J., W. B. Curry, and N. Slowey (1999), A geostrophic transport estimate for the Florida Current from the oxygen isotope composition of benthic foraminifera, Paleoceanography, 14, 360-373, doi:10.1029/1999PA900001.

Manighetti, B., and I. N. McCave (1995), Late glacial and Holocene palaeocurrents around Rockall Bank, NE Atlantic Ocean, Paleoceanography, 10, 611-626, doi:10.1029/94PA03059.

Marchal, O., and W. B. Curry (2008), On the abyssal circulation in the glacial Atlantic, J. Phys. Oceanogr., 38, 2014-2037, doi:10.1175/2008JPO3895.1

Marchitto, T. M., S. J. Lehman, J. D. Ortiz, J. Flückiger, and A. van Geen (2007), Marine radiocarbon evidence for the mechanism of deglacial atmospheric $\mathrm{CO}_{2}$ rise, Science, 316, 1456-1459, doi:10.1126/science.1138679.

MARGO Project Members et al. (2009), Constraints on the magnitude and patterns of ocean cooling at the Last Glacial Maximum, Nat. Geosci., 2, 127-132, doi:10.1038/ngeo411.

Marshall, J., A. Adcroft, C. Hill, L. Perelman, and C. Heisey (1997), A finite-volume, incompressible Navier Stokes model for studies of the ocean on parallel computers, J. Geophys. Res., 102, 5753-5766, doi:10.1029/96JC02775.

Matsumoto, K., T. Oba, J. Lynch-Stieglitz, and H. Yamamoto (2002), Interior hydrography and circulation of the glacial Pacific Ocean, Quat. Sci. Rev., 21, 1693-1704, doi:10.1016/S0277-3791(01)00142-1.

Matsumoto, K., T. Hashioka, and Y. Yamanaka (2007), Effect of temperature-dependent organic carbon decay on atmospheric pCO ${ }_{2}$, J. Geophys. Res., 112, G02007, doi:10.1029/2006JG000187.

McCave, I. N., and I. R. Hall (2006), Size sorting in marine muds: Processes, pitfalls, and prospects for paleoflow-speed proxies, Geochem. Geophys. Geosyst., 7, Q10N05, doi:10.1029/2006GC001284.

McCave, I. N., B. Manighetti, and N. A. S. Beveridge (1995), Circulation in the glacial North Atlantic inferred from grain-size measurements, Nature, 374, 149-152, doi:10.1038/374149a0.

McManus, J. F., R. Francois, J.-M. Gherardi, L. D. Keigwin, and S. Brown-Leger (2004), Collapse and rapid resumption of Atlantic meridional circulation linked to deglacial climate changes, Nature, 428, 834-837, doi:10.1038/nature02494.

Merkel, U., M. Prange, and M. Schulz (2010), ENSO variability and teleconnections during glacial climates, Quat. Sci. Rev., 29, 86-100, doi:10.1016/j.quascirev.2009.11.006.

Mix, A., E. Bard, and R. Schneider (2001), Environmental processes of the Ice Age: Land, oceans, glaciers (EPILOG), Quat. Sci. Rev., 20, 627-657, doi:10.1016/S0277-3791(00)00145-1.

Muglia, J., and A. Schmittner (2015), Glacial Atlantic overturning increased by wind stress in climate models, Geophys. Res. Lett., 42, 9862-9868, doi:10.1002/2015GL064583.

Negre, C., R. Zahn, A. L. Thomas, P. Masqué, G. M. Henderson, G. Martínez-Méndez, I. R. Hall, and J. L. Mas (2010), Reversed flow of Atlantic deep water during the Last Glacial Maximum, Nature, 468, 84-89, doi:10.1038/nature09508.

Oka, A., A. Abe-Ouchi, M. O. Chikamoto, and T. Ide (2011), Mechanisms controlling export production at the LGM: Effects of changes in oceanic physical fields and atmospheric dust deposition, Global Biogeochem. Cycles, 25, GB2009, doi:10.1029/2009GB003628.

Oliver, K. I. C., B. A. A. Hoogakker, S. Crowhurst, G. M. Henderson, R. E. M. Rickaby, N. R. Edwards, and H. Elderfield (2010), A synthesis of marine sediment core $\delta^{13} \mathrm{C}$ data over the last 150000 years, Clim. Past, 6, 645-673, doi:10.5194/cp-6-645-2010.

Otto-Bliesner, B. L., C. D. Hewitt, T. M. Marchitto, E. Brady, A. Abe-Ouchi, M. Crucifix, and S. Murakami (2007), Last Glacial Maximum ocean thermohaline circulation: PMIP2 model intercomparisons and data constraints, Geophys. Res. Lett., 34, L12706, doi:10.1029/2007GL029475.

Paul, A., and M. Losch (2012), Perspectives of parameter and state estimation in paleoclimatology, in Climate Change, Proceedings of the Milutin Milankovitch 130th Anniversary Symposium, Part 2, edited by A. Berger, F. Mesinger, and D. Sijacki, pp. 93-105, Springer, Heidelberg.

Paul, A., and C. Schäfer-Neth (2003), Modeling the water masses of the Atlantic Ocean at the Last Glacial Maximum, Paleoceanography, 18, 1058, doi:10.1029/2002PA000783.

Peltier, W. R. (2004), Global glacial isostasy and the surface of the Ice-Age Earth: The ICE-5G (VM2) model and GRACE, Annu. Rev. Earth Planet. Sci., 32, 111-149, doi:10.1146/annurev.earth.32.082503.144359.

Peterson, C. D., L. E. Lisiecki, and J. V. Stern (2014), Deglacial whole-ocean $\delta^{13} \mathrm{C}$ change estimated from 480 benthic foraminiferal records, Paleoceanography, 29, 549-563, doi:10.1002/2013PA002552.

Piotrowski, A. M., S. L. Goldstein, S. R. Hemming, and R. G. Fairbanks (2005), Temporal relationships of carbon cycling and ocean circulation at glacial boundaries, Science, 307, 1933-1938, doi:10.1126/science.1104883.

Rae, J. W. B., M. Sarnthein, G. L. Foster, A. Ridgwell, P. M. Grootes, and T. Elliott (2014), Deep water formation in the North Pacific and deglacial $\mathrm{CO}_{2}$ rise, Paleoceanography, 29, 645-667, doi:10.1002/2013PA002570.

Rahmstorf, S. (1996), On the freshwater forcing and transport of the Atlantic thermohaline circulation, Clim. Dyn., 12, 799-811, doi: $10.1007 / \mathrm{s} 003820050144$.

Ritz, S. P., T. F. Stocker, J. O. Grimalt, L. Menviel, and A. Timmermann (2013), Estimated strength of the Atlantic overturning circulation during the last deglaciation, Nat. Geosci., 6, 208-212, doi:10.1038/ngeo1723. 
Rutberg, R. L., and S. L. Peacock (2006), High-latitude forcing of interior ocean $\delta^{13}$ C, Paleoceanography, 21, PA2012, doi:10.1029/2005PA001226.

Sarnthein, M., R. Gersonde, S. Niebler, U. Pflaumann, R. Spielhagen, J. Thiede, G. Wefer, and M. Weinelt (2003), Overview of glacial Atlantic Ocean mapping (GLAMAP 2000), Paleoceanography, 18, 1030, doi:10.1029/2002PA000769.

Schmidt, G. A., G. R. Bigg, and E. J. Rohlin (1999), Global Seawater Oxygen-18 Database, NASA Goddard Inst. of Space Sci., New York.

Schmittner, A., and C. J. Somes (2016), Complementary constraints from carbon $\left({ }^{13} \mathrm{C}\right)$ and nitrogen $\left({ }^{15} \mathrm{~N}\right)$ isotopes on the glacial ocean's soft-tissue biological pump, Paleoceanography, 31, 669-693, doi:10.1002/2015PA002905.

Schmittner, A., N. Gruber, A. C. Mix, R. M. Key, A. Tagliabue, and T. K. Westberry (2013), Biology and air-sea gas exchange controls on the distribution of carbon isotope ratios $\left(\delta^{13} \mathrm{C}\right)$ in the ocean, Biogeosciences, 10, 5793-5816, doi:10.5194/bg-10-5793-2013.

Schmittner, A., J. A. M. Green, and S.-B. Wilmes (2015), Glacial ocean overturning intensified by tidal mixing in a global circulation model Geophys. Res. Lett., 42, 4014-4022, doi:10.1002/2015GL063561.

Sigman, D. M., and E. A. Boyle (2000), Glacial/interglacial variations in atmospheric carbon dioxide, Nature, 407, $859-869$.

Solomon, S., Q. Dahe, and M. Manning (2007), Technical summary, in Climate Change 2007, Contribution of Working Group I to the Fourth Assessment Report of the Intergovernmental Panel on Climate Change, pp. 19-91, Cambridge Univ. Press, Cambridge, U. K., and New York.

Stammer, D., C. Wunsch, R. Giering, C. Eckert, P. Heimbach, J. Marotzke, A. Adcroft, C. N. Hill, and J. Marshall (2002), Global ocean circulation during 1992-1997, estimated from ocean observations and a general circulation model, J. Geophys. Res., 107, 3118, doi:10.1029/2001JC000888.

Stammer, D., M. Balmaseda, P. Heimbach, A. Köhl, and A. Weaver (2016), Ocean data assimilation in support of climate applications: Status and perspectives, Annu. Rev. Mar. Sci., 8, 491-518, doi:10.1146/annurev-marine-122414-034113.

Stephens, B. B., and R. F. Keeling (2000), The influence of Antarctic sea ice on glacial-interglacial $\mathrm{CO}_{2}$ variations, Nature, 404, $171-174$

Tagliabue, A., L. Bopp, D. M. Roche, N. Bouttes, J.-C. Dutay, R. Alkama, M. Kageyama, E. Michel, and D. Paillard (2009), Quantifying the roles of ocean circulation and biogeochemistry in governing ocean carbon-13 and atmospheric carbon dioxide at the Last Glacial Maximum, Clim. Past, 5, 695-706.

Toggweiler, J. R. (2008), Origin of the 100,000-year timescale in Antarctic temperatures and atmospheric $\mathrm{CO}_{2}$, Paleoceanography, 23 , PA2211, doi:10.1029/2006PA001405.

Toggweiler, J. R., J. L. Russell, and S. R. Carson (2006), Midlatitude westerlies, atmospheric $\mathrm{CO}_{2}$, and climate change during the ice ages, Paleoceanography, 21, PA2005, doi:10.1029/2005PA001154.

Troupin, C., et al. (2012), Generation of analysis and consistent error fields using the data interpolating variational analysis (DIVA), Ocean Modell., 52-53, 90-101, doi:10.1016/j.ocemod.2012.05.002.

Tschumi, T., F. Joos, M. Gehlen, and C. Heinze (2011), Deep ocean ventilation, carbon isotopes, marine sedimentation and the deglacial $\mathrm{CO}_{2}$ rise, Clim. Past, 7, 771-800, doi:10.5194/cp-7-771-2011.

Winguth, A. M. E., D. Archer, E. Maier-Reimer, and U. Mikolajewicz (2000), Paleonutrient data analysis of the glacial Atlantic using an adjoint ocean general circulation model, in Geophys. Monogr. Ser., vol. 114, pp. 171-183, AGU, Washington D. C., doi:10.1029/GM114p0171.

Wunsch, C. (1996), The Ocean Circulation Inverse Problem, Cambridge Univ. Press, Cambridge.

Wunsch, C. (2003), Determining paleoceanographic circulations, with emphasis on the Last Glacial Maximum, Quat. Sci. Rev., 22, 371-385, doi:10.1016/S0277-3791(02)00177-4

Wunsch, C. (2016), Last Glacial Maximum and deglacial abyssal seawater oxygen isotopic ratios, Clim. Past Discuss., 2016, 1-23, doi:10.5194/cp-2015-193.

Wunsch, C., and P. Heimbach (2006), Estimated decadal changes in the North Atlantic Meridional Overturning Circulation and heat flux 1993 2004, J. Phys. Oceanogr., 36(11), 2012-2024, doi:10.1175/JPO2957.1.

Wunsch, C., and P. Heimbach (2008), How long to oceanic tracer and proxy equilibrium?, Quat. Sci. Rev., 27, 637-651, doi:10.1016/j.quascirev.2008.01.006

Yamanaka, Y., and E. Tajika (1996), The role of the vertical fluxes of particulate organic matter and calcite in the oceanic carbon cycle: Studies using an ocean biogeochemical general circulation model, Global Biogeochem. Cycles, 10, 361-382, doi:10.1029/96GB00634.

Yu, E.-F., R. Francois, and M. P. Bacon (1996), Similar rates of modern and last-glacial ocean thermohaline circulation inferred from radiochemical data, Nature, 379, 689-694, doi:10.1038/379689a0. 